\title{
Proteomic Quantification of Human Blood-Brain Barrier SLC and ABC Transporters in Healthy Individuals and Dementia Patients
}

DOI:

10.1021/acs.molpharmaceut.8b01189

\section{Document Version}

Accepted author manuscript

Link to publication record in Manchester Research Explorer

Citation for published version (APA):

Al-Majdoub, Z., Al Feteisi, H., Achour, B., Warwood, S., Neuhoff, S., Rostami-Hodjegan, A., \& Barber, J. (2019). Proteomic Quantification of Human Blood-Brain Barrier SLC and ABC Transporters in Healthy Individuals and Dementia Patients. Molecular Pharmaceutics, 16(3), 1220-1233.

https://doi.org/10.1021/acs.molpharmaceut.8b01189

\section{Published in:}

Molecular Pharmaceutics

\section{Citing this paper}

Please note that where the full-text provided on Manchester Research Explorer is the Author Accepted Manuscript or Proof version this may differ from the final Published version. If citing, it is advised that you check and use the publisher's definitive version.

\section{General rights}

Copyright and moral rights for the publications made accessible in the Research Explorer are retained by the authors and/or other copyright owners and it is a condition of accessing publications that users recognise and abide by the legal requirements associated with these rights.

\section{Takedown policy}

If you believe that this document breaches copyright please refer to the University of Manchester's Takedown Procedures [http://man.ac.uk/04Y6Bo] or contact uml.scholarlycommunications@manchester.ac.uk providing relevant details, so we can investigate your claim.

\section{OPEN ACCESS}


This document is confidential and is proprietary to the American Chemical Society and its authors. Do not copy or disclose without written permission. If you have received this item in error, notify the sender and delete all copies.

\section{Proteomic Quantification of Human Blood-Brain Barrier SLC and ABC Transporters in Healthy Individuals and Dementia Patients}

\begin{tabular}{|r|l|}
\hline Journal: & Molecular Pharmaceutics \\
\hline Manuscript ID & mp-2018-01189c.R1 \\
\hline Manuscript Type: & Article \\
\hline Author: & O2-Jan-2019 \\
\hline Complete List of Authors: & $\begin{array}{l}\text { Al-Majdoub, Zubida; University of Manchester, Centre for Applied } \\
\text { Pharmacokinetic Research; Division of Pharmacy and Optometry } \\
\text { Al Feteisi, Hajar; University of Manchester, Centre for Applied } \\
\text { Pharmacokinetic Research; Division of Pharmacy and Optometry } \\
\text { Achour, Brahim; University of Manchester, Centre for Applied } \\
\text { Pharmacokinetic Research; Division of Pharmacy and Optometry } \\
\text { Warwood, Stacey; University of Manchester, Biological Mass } \\
\text { Spectrometry Core Facility } \\
\text { Neuhoff, Sibylle; Simcyp Ltd. , (a Certara company) } \\
\text { Rostami-Hodjegan, Amin; University of Manchester, Centre for Applied } \\
\text { Pharmacokinetic Research; Division of Pharmacy and Optometry; Simcyp } \\
\text { Ltd. , (a Certara company) } \\
\text { Barber, Jill; University of Manchester, Centre for Applied Pharmacokinetic } \\
\text { Research; Division of Pharmacy and Optometry }\end{array}$ \\
\hline
\end{tabular}

\section{SCHOLARONE ${ }^{\text {m }}$ Manuscripts}




\title{
Proteomic Quantification of Human Blood-Brain
}

\author{
Barrier SLC and ABC Transporters in Healthy
}

\section{Individuals and Dementia Patients}

\section{Zubida M. Al-Majdoub ${ }^{*}$, Hajar Al Feteisi', Brahim Achour ${ }^{1}$, Stacey Warwood ${ }^{2}$, Sibylle Neuhoff ${ }^{3}$, Amin Rostami-Hodjegan ${ }^{1,3}$, Jill Barber ${ }^{*}$}

${ }^{1}$ Centre for Applied Pharmacokinetic Research (CAPKR), University of Manchester, UK.

${ }^{2}$ Biological Mass Spectrometry Core Facility, University of Manchester, UK.

${ }^{3}$ Certara UK Limited, Simcyp Division, Level 2-Acero, 1 Concourse Way, Sheffield, S1 2BJ, UK.

\begin{abstract}
*To whom correspondence should be addressed: Zubida.al-majdoub@manchester.ac.uk; Jill.barber@manchester.ac.uk
\end{abstract}

\begin{abstract}
KEYWORDS: Blood-Brain Barrier (BBB), Alzheimer's Disease (AD), Dementia with Lewy Bodies (DLB), Solute carrier (SLC) and ATP-binding cassette (ABC) transporters.
\end{abstract}




\begin{abstract}
The Blood-Brain Barrier (BBB) maintains brain homeostasis by controlling traffic of molecules from the circulation into the brain. This function is predominantly dependent on proteins expressed at the BBB, especially transporters and tight junction proteins. Alterations to the level and function of BBB proteins can impact on the susceptibility of the central nervous system to exposure to xenobiotics in the systemic circulation with potential consequent effects on brain function. In this study, expression profiles of drug transporters and solute carriers in the BBB were assessed in tissues from healthy individuals $(n=12)$, Alzheimer's patients $(\mathrm{n}=5)$ and Dementia with Lewy Bodies patients $(\mathrm{n}=5)$, using targeted, AMRT (Accurate Mass Retention Time) and global proteomic methods. A total of 66 transporters were quantified, 19 for the first time in the BBB. A further 20 novel transporters were identified but not quantified. The global proteomic method identified another $3333 \mathrm{BBB}$ proteins. Transporter abundances, taken together with the scaling factor microvessel protein content per unit tissue (BMvPGB also measured here) can be used in quantitative systems pharmacology models predicting drug disposition in the brain and permitting dose adjustment (precision dosing) in special populations of patients, such as those with dementia. Even in this small study, we see differences in transporter profile between healthy and diseased brain tissue.
\end{abstract}




\section{INTRODUCTION}

The two main barrier interfaces between the blood and the brain are the blood-cerebral spinal fluid barrier (BCSFB) across the choroid plexus epithelial cells and the blood-brain barrier (BBB) across the cerebral endothelial cells. These barriers play vital roles in controlling transport between systemic blood and brain tissue; this means that they control the concentration of drugs in the central nervous system (CNS) and this in turn affects their efficacy and toxicity. ${ }^{1,2}$ The contribution of proteins regulating traffic of molecules across the $\mathrm{BBB}$ to the maintenance of brain homeostasis, and their effect on the disposition of substrate drugs targeted at CNS conditions is widely appreciated. ${ }^{3,4}$ These transporters at the $\mathrm{BBB}$ act as gatekeepers to the CNS and play a critical role in drug and xenobiotic brain disposition. $^{5}$

Membrane transporters can be categorized molecularly into two major superfamilies: solute carriers (SLCs) and ABC-type efflux transporters. Based on function, transporters serve two main roles: efflux and uptake (influx) transport. All ATP-dependent transporters are efflux transporters from the point of view of the cell. However, SLCs can work as uptake, efflux, as well as equilibrative transporters. These transporters are a key protective element of the $\mathrm{BBB}$, actively transporting a wide variety of xenobiotics back into the circulation. Uptake transporters, such as several SLCs, can facilitate uptake into the cerebrospinal fluid from the blood. ${ }^{6}$

One of the major challenges of modern day medicine is the understanding, diagnosis, and treatment of complex and heterogeneous age-related disorders, such as dementia. Despite the significant commercial opportunities that exist, attempts to discover effective drugs to treat neurological diseases have proved so difficult that many companies have withdrawn 
from the field. ${ }^{7}$ Compared with other disease areas, failure rates in clinical trials are high for neurological disease largely due to the complexity of the human brain. ${ }^{8}$

The most common cause of dementia is Alzheimer's disease (AD), which is characterized by a progressive decline in memory and cognitive functions. ${ }^{9}$ The classical neuropathological hallmarks of $\mathrm{AD}$ are extracellular deposits of amyloid-beta and tau proteins. ${ }^{10,11}$ Recent evidence suggests that the neurodegenerative process that leads to the development of $\mathrm{AD}$ is highly associated with a significant dysfunction of the BBB. ${ }^{12}$ Unlike the genome, which is relatively static, the proteome is extremely dynamic and constantly changing in response to internal (e.g. ageing, disease status) and external (e.g. toxin exposure) stimuli. Possibly, alterations in the expression of proteins have functional consequences and lead to a variety of pathophysiological conditions. Indeed, proteome analysis has been suggested to hold the key to improving understanding, diagnosis, and treatment of $\mathrm{AD}$, as well as monitoring the progression of the disease. ${ }^{13,14}$ It is therefore crucial to understand changes in transporter expression and evaluate inter-individual variation in protein levels between healthy and diseased brains.

In vitro disposition data obtained from cellular brain models, such as neurovascular endothelial cells, are commonly scaled using in vitro-in vivo extrapolation (IVIVE) to ultimately predict drug/xenobiotic disposition in vivo. Helms et al. evaluated the advantages and disadvantages of available brain cell-culture models and commented that, to date, there is no ideal BBB in vitro model. ${ }^{15}$ IVIVE relies upon robust estimates of physiologicallyrelevant scaling factors, including protein content of the microvascular fraction (brain microvessels protein per gram of brain, BMvPGB) and transporter expression at the BBB. These data are essential for filling the existing gaps in models for human brain disease and prediction of appropriate drug dosing for different disease populations. ${ }^{16}$ It is notable that there are limited data in the literature for the protein content scaling factor (BMvPGB), which 
has only been reported in healthy individuals, ${ }^{17}$ and therefore, there is a need to assess both protein content and transporter expression in health and dementia.

The aim of this study was to investigate alterations in the proteomic composition of the blood-brain barrier between healthy and dementia brains, focusing on drug and endogenous transporters, using a proteomic strategy that combines both targeted and global analyses. In addition, the total protein content of the microvascular fraction (BMvPGB) was assessed in healthy and dementia brains. Brain samples were from 22 donors, consisting of healthy individuals and patients with either AD or DLB.

\section{MATERIALS AND METHODS}

Materials and chemicals were purchased from Sigma-Aldrich (Poole, UK) unless otherwise indicated. The unlabeled non-naturally occurring peptide (NNOP) calibrator (Glufibrinopeptide B (EGVNDNEEGFFSAR, purity 95\%) was purchased from Severn Biotech (Worcestershire, UK). Lysyl Endopeptidase (Lys-C) was purchased from Wako (Osaka, Japan). COmplete Mini, EDTA-free protease inhibitor cocktail, and recombinant proteomicgrade trypsin were supplied by Roche Applied Sciences (Mannheim, Germany). Two TransCATs (artificial proteins, see below) were used; the Liver TransCAT protein was produced in-house as previously described. ${ }^{18}$ The Brain TransCAT was designed and expressed in-house. Both genes were synthesized by Entelechon GmbH (Regensburg, Germany) and the QconCAT proteins were used for quantification of brain transporters. Bicinchoninic acid (BCA) protein assay kit was purchased from Pierce (Rockford, IL, USA). PiColorLock ${ }^{\mathrm{TM}}$ phosphate detection system was purchased from Innova Biosciences (Cambridge, UK). Solvents used in this study were of HPLC Chromasolv grade (Thermo Fisher, Waltham, MA). 


\section{QconCAT standards "TransCATs"}

Two transporter QconCAT "TransCAT" standards were used in this study: named Liver TransCAT and Brain TransCAT. The "Liver TransCAT" standard has previously been described. ${ }^{18}$ The "Brain TransCAT" is a novel QconCAT for the quantification of human brain drug transporter proteins that have a crucial role in disposition of drugs and endogenous compounds across the BBB. The unique tryptic peptides making up the Brain TransCAT were two each from nine transporters (ABCA1, ABCA2, ABCC5, SLC7A5, SLC16A1, SLC22A4, SLC29A2, SLCO2B1, SLCO1C1) and three each from seven transporters (ABCA7, ABCC1, SLC22A2, SLC22A6, SLC22A8, SLC47A2, SLC29A1). Two peptides unique to each neurovascular unit cell marker protein of endothelial cells (GLUT1, PECAM1), pericytes (CSPG4, NG2), astrocytes (GFAP) and neurons (SYP) were also included to assess quantitatively the enrichment and the level of contamination of the isolated microvessels. In addition, two receptor proteins, vascular endothelial growth factor receptor 2 (KDR) and nuclear receptor subfamily 1 group I member 2 (NR1I2), represented by two peptides each, were included.

The candidate peptide list was generated by combining sequences from SRMAtlas (www.srmatlas.org) with those predicted to ionize efficiently in addition to peptides identified experimentally by global LC-MS/MS analysis of brain microvessel proteins. Peptides containing methionine or cysteine residues and non-unique or membrane embedded sequences were excluded for the final list. Peptides were checked against the Uniprot database for known polymorphisms and post-translational modifications. Finally, a Glufibrinopeptide B (GFB) peptide was included to enable quantification of the TransCAT itself. The full list of peptides of the Brain TransCAT is included in Table ES1. 


\section{Brain TransCAT gene synthesis and expression}

The DNA construct of the TransCAT was produced by PolyQuant GmbH (Regensburg, Germany) using the expression vector pET21a with codons optimized for both expression and minimized secondary structure formation in mRNA. His-tag was added to the C- terminus to enable purification. The TransCAT sequence was fused to a sequence comprising peptides from E. coli core ribosomal proteins that had previously served as a QconCAT for those proteins ${ }^{19}$ and sacrificial sequences were added to the N-terminus to protect the proteotypic peptides from potential N-terminal degradation. TransCAT transformation, expression in ${ }^{13} \mathrm{C}$ heavy-isotope enriched medium and purification were performed as previously described. ${ }^{18}$ TransCAT $(77 \mathrm{kDa})$ was then added in isotopically labelled form to the brain tissue prior to protease digestion. Proteolysis allows release of standard peptides in 1:1 stoichiometry, leading to the estimation of the concentrations of the target proteins using the QconCAT peptides as standards.

The Brain TransCAT was quantified using a label-free AQUA peptide "Glufibrinopeptide B (GFB)". A known amount of GFB peptide was added to the TransCAT preparation and analyzed simultaneously was sample proteins. LC-MS/MS analysis of the TransCAT-analyte mixture yields the relative intensity of the TransCAT and analyte ions, and since the TransCAT is present at a known concentration, the quantity of analyte can be calculated directly.

\section{Human brain samples}

Frozen brain frontal cortexes of 22 donors were supplied by the Manchester Brain Bank (University of Manchester) with approval for collection, transfer, storage and handling (Newcastle and North Tyneside REC) under Manchester Brain Bank generic tissue bankethics (H09/0906). The samples were supplied from healthy $(n=12)$, DLB $(n=5)$ and AD $(n=5)$. Donor demographic and clinical details are presented in Table S1. These samples were 
used for global and targeted proteomic analysis of isolated brain microvessels as described below.

\section{Tissue preparation}

Microvessels were isolated using optimized tissue processing methods, as previously described, ${ }^{20}$ with some modifications. Briefly, 3 grams of frozen human brain tissue were thawed on ice and all subsequent steps were performed on ice. Brain cortex was finely minced and homogenized using 20 up-and-down non-rotated strokes in lysis buffer (Buffer A) using volumes of $4-5 \mathrm{~mL} / \mathrm{g}$ tissue $\left(8 \mathrm{~g} / \mathrm{L} \mathrm{NaCl}, 400 \mathrm{mg} / \mathrm{L} \mathrm{KCl}, 185.4 \mathrm{mg} / \mathrm{L} \mathrm{CaCl}\right.$ Cl$_{2} \cdot 2 \mathrm{H}_{2} \mathrm{O}$, $60 \mathrm{mg} / \mathrm{L} \mathrm{KH}_{2} \mathrm{PO}_{4}, 200 \mathrm{mg} / \mathrm{L} \mathrm{MgSO} \cdot \cdot 7 \mathrm{H}_{2} \mathrm{O}, 350 \mathrm{mg} / \mathrm{L} \mathrm{NaHCO}_{3}, 1 \mathrm{~g} / \mathrm{L}$ dextrose anhydrous, $90 \mathrm{mg} / \mathrm{L} \mathrm{Na}_{2} \mathrm{HPO}_{4} \cdot 7 \mathrm{H}_{2} \mathrm{O}, \mathrm{pH}$ 7.4) in a $50 \mathrm{~mL}$ tube. Protease inhibitor was added to the homogenate to prevent proteolytic degradation in subsequent sample preparation steps, according to the manufacturer's instructions ( 1 tablet per $10 \mathrm{~mL})$. The homogenates were centrifuged at $2000 \mathrm{~g}$ for $10 \mathrm{~min}$ at $4^{\circ} \mathrm{C}$. The resulting pellet was suspended in $16 \%$ dextran and subsequently centrifuged at 5,500 $\mathrm{g}$ for $15 \mathrm{~min}$ at $4^{\circ} \mathrm{C}$. The supernatant was transferred to a fresh tube and centrifuged again in a similar way before suspending the two pellets in $10 \mathrm{~mL}$ of Buffer B (lysis buffer containing $5 \mathrm{mg} / \mathrm{mL}$ bovine serum albumin [BSA]). The suspension was then passed through a $20 \mu \mathrm{m}$ nylon mesh, using $<20 \mathrm{~mL}$ Buffer B to rinse the tube and mesh of residual homogenate. The retained fraction was transferred to centrifuge tubes and centrifuged at $2000 \mathrm{~g}$ for $5 \mathrm{~min}$ at $4^{\circ} \mathrm{C}$. The suspended pellet was then dissolved in $1 \mathrm{~mL}$ Buffer B and further centrifuged at $1,000 \mathrm{~g}$ for $5 \mathrm{~min}$ at $4^{\circ} \mathrm{C}$. Finally, the microvessels pellet was resuspended in $1 \mathrm{~mL}$ isotonic buffer $(1 \mathrm{M}$ Tris- $\mathrm{HCl}, 10 \mathrm{mM} \mathrm{NaCl}, 1.5 \mathrm{mM} \mathrm{MgCl}$, pH 7.4) and sonicated using a S220 Focused-ultrasonicator (COVARIS, UK), then stored at $80^{\circ} \mathrm{C}$ until further analysis. Protein content in the microvessels and homogenates was determined using Bicinchoninic acid (BCA) protein assay kit according to the manufacturer's instructions. 


\section{Measurement of ATPase enzymatic activity}

To assess the level of enrichment of microvessel proteins, adenosine triphosphatase (ATPase) activity was determined in isolated microvessels and homogenates by a colorimetric method. The assay was performed according to manufacturer's protocol.

\section{Sample preparation of brain microvessels for global and targeted proteomics}

The microvessels protein was digested on filter units. The filter-aided sample preparation (FASP) protocol used here is an optimized version of the previously reported $\operatorname{method}^{19,21}$ and the detailed procedure is described in our previous study. ${ }^{20}$ Briefly, the protocol involved sodium deoxycholate incubation for solubilisation. We chose FASP over in-solution digestion for its simplicity, time-efficiency, efficient removal of contaminants, and its applicability to clinically-relevant enzymes and transporters. ${ }^{20}$

Three technical replicates for each of the 22 human brain microvessel samples were prepared. The first technical replicate was spiked with Liver TransCAT only, the second replicate was spiked with Liver and Brain TransCATs and the third replicate was spiked with Brain TransCAT only. A mixture of protein extracts $(20-50 \mu \mathrm{g})$ and TransCATs (250-500 fmol) were solubilized with $10 \%(\mathrm{w} / \mathrm{v})$ sodium deoxycholate at room temperature for $10 \mathrm{~min}$, and cysteine disulfide bonds were reduced by adding $0.1 \mathrm{M}$ Tris- $\mathrm{HCl}$ buffer, $\mathrm{pH} 8.5$, containing $60 \mathrm{mM}$ dithiothreitol and $8 \mathrm{M}$ urea followed by incubation with mixing at $56^{\circ} \mathrm{C}$ for 30 min. Ultracel 10,000 MWCO (molecular weight cut-off of $10 \mathrm{kDa}$ ) centrifugal filter units (Amicon Ultra, Merck) were washed using two steps of centrifugation at $14,000 \mathrm{~g}$ for 20 minutes with $200 \mu \mathrm{L}$ of $8 \mathrm{M}$ urea in $0.1 \mathrm{M}$ Tris-HCl, $\mathrm{pH}$ 8.5. Solubilized and reduced protein samples were then added to the filter units, followed by a centrifugation step at $14,000 \mathrm{~g}$ for $30 \mathrm{~min}$. Protein extracts were buffer-exchanged using $8 \mathrm{M}$ urea in $0.1 \mathrm{M}$ Tris$\mathrm{HCl}, \mathrm{pH} 8.5$, by centrifugation at $14,000 \mathrm{~g}$ for $20 \mathrm{~min}$. Alkylation of reduced disulfide bonds was carried out by incubation with $200 \mu \mathrm{L}$ of $50 \mathrm{mM}$ iodacetamide in $8 \mathrm{M}$ urea and $0.1 \mathrm{M}$ 
Tris- $\mathrm{HCl}, \mathrm{pH} 8.5$, in the dark for 30 min followed by centrifugation as above. A $200 \mu \mathrm{L}$ volume of $8 \mathrm{M}$ urea in $0.1 \mathrm{M}$ Tris- $\mathrm{HCl}, \mathrm{pH} 8.5$, was added and centrifugation was carried out to remove the alkylating agent, followed by three buffer exchanges with $200 \mu \mathrm{L}$ of $1 \mathrm{M}$ urea in $50 \mathrm{mM}$ ammonium bicarbonate buffer, $\mathrm{pH}$ 8.0. A volume of $40 \mu \mathrm{L}$ of $50 \mathrm{mM}$ ammonium bicarbonate buffer, $\mathrm{pH} 8.0$, was added to the filter to prevent evaporation of the digestion mix. Lys-C (10 $\mu \mathrm{L}, 0.1 \mathrm{mg} / \mathrm{ml})$, at mass ratio 1:50 enzyme:protein, was added and samples incubated at $30^{\circ} \mathrm{C}$ for $3 \mathrm{~h}$, followed by a second dose of Lys-C and incubation for another 3 h. Trypsin $(10 \mu \mathrm{L}, 0.2 \mathrm{mg} / \mathrm{ml})$, at mass ratio 1:25 enzyme:protein was added and incubated overnight $(16 \mathrm{~h})$ at $37^{\circ} \mathrm{C}$. The Lys-C treatment step was repeated to increase digestion efficiency and minimize missed cleavages. The samples were then centrifuged at $14000 \mathrm{~g}$ for 20 min and $100 \mu \mathrm{L}$ of $0.5 \mathrm{M} \mathrm{NaCl}$ solution was added to the filter followed by centrifugation at $14,000 \mathrm{~g}$ for $20 \mathrm{~min}$ to collect the remaining peptides. Samples were then vacuum dried and desalted on a C18 spin-column, followed by analysis by targeted LC-MRM (multi reaction monitoring) MS/MS on a QTrap 6500 mass spectrometer and global LC-MS/MS on a Q Exactive Orbitrap. Amount of total protein between 1.2-1.5 $\mu \mathrm{g}$ was loaded on a QTrap 6500 mass spectrometer for MRM analysis.

\section{Global LC-MS/MS proteomic analysis}

For LC-MS/MS analysis using the Q Exactive platform, desalted samples were resuspended in $10 \mu \mathrm{L}$ of loading buffer (5\% acetonitrile in $0.1 \%$ formic acid [FA]) and $1 \mu \mathrm{L}$ (2.5 $\mu \mathrm{g}$ total protein) was loaded onto an UltiMate® 3000 (Dionex, Surrey, UK) liquid chromatography (LC) system coupled on-line to a Q Exactive ${ }^{\mathrm{TM}}$ HF Hybrid QuadrupoleOrbitrap $^{\mathrm{TM}}$ mass spectrometer (Thermo Fisher, Bremen, Germany). Peptides were reversedphase separated on a CSH C18 analytical column $(250 \mathrm{~mm} \times 75 \mu \mathrm{m}$ i.d., $1.7 \mu \mathrm{m})($ Waters, UK). A multi-step gradient was used from 4\% Buffer B (100\% acetonitrile, 0.1\% FA) and $96 \%$ Buffer A $(0.1 \%$ FA in HPLC water) to $60 \%$ Buffer B over 165 min at a flow rate of 300 
$\mathrm{nL} \min ^{-1}$. The LC eluent was injected into the mass spectrometer. All $\mathrm{m} / \mathrm{z}$ values of eluting ions were measured in an Orbitrap MS, set at a resolution of 120,000. Data dependent scans were employed to automatically select the 12 most abundant ions for fragmentation by higher-energy collisional dissociation (HCD) in the quadrupole mass analyser. Only peptide ions with charge states of $2+, 3+$, and $4+$ were selected for fragmentation. Finally, the measurement of the resulting fragment ions was performed in the Orbitrap analyser, set at a resolution of 30,000 .

\section{MRM assays and targeted LC-MS/MS analysis}

Peptide samples were analysed by LC-MRM-MS/MS using an UltiMate ${ }^{\circledR} 3000$ Rapid Separation LC (RSLC, Thermo Fisher Scientific, Waltham, MA) coupled to a 6500 QTRAP (SCIEX, Framingham, MA) mass spectrometer. Peptide mixtures were separated using a gradient from $95 \%$ Buffer A $(0.1 \% \mathrm{FA}$ in HPLC water) and $5 \%$ Buffer B $(0.1 \% \mathrm{FA}$ in

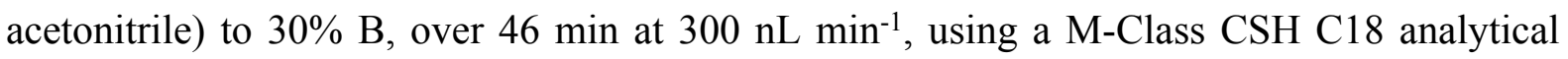
column (250 mm x $75 \mu \mathrm{m}$ i.d., $1.7 \mu \mathrm{m})$ (Waters, Milford, MA).

Signature peptide sequences from both TransCATs were concatenated in silico, along with the sequence of Glu-fibrinopeptide B (GFB), used as an internal standard for the QconCATs. Skyline version 4.1

(https://skyline.ms/project/home/software/Skyline/begin.view) ${ }^{22}$ was used to generate theoretical transitions for each peptide in the sequence. The peptide settings were as follows: digestion enzyme was trypsin, no missed cleavages were allowed. Peptide lengths were 6-20 residues, and carbamidomethylation (C) was included as a fixed modification, oxidation (M) as a variable modification. The transition settings were as follows: precursor charge states of $2+$ and $3+$ were included, with y product ions included as $1+$ only. Products ions (2-5) were selected from each precursor ion. In addition, any product ions resulting from fragmentation 
$\mathrm{N}$-terminal to proline and C-terminal to glutamic acid or aspartic acid were included. The $\mathrm{m} / \mathrm{z}$ range was set to a minimum of $350 \mathrm{Th}$ and a maximum of $1250 \mathrm{Th}$.

\section{Data analysis and protein quantification}

For label-free quantification, raw Orbitrap MS files were imported into Progenesis software (Nonlinear Dynamics, version 4.0). Data in Mascot generic format (mgf) were exported directly from Progenesis, and MS/MS spectra were searched using MASCOT against a human proteome database containing 71,599 entries (UniProt, May 2017) and a decoy database of the predicted proteome for Homo sapiens. The search criteria were set as follows: Full tryptic specificity was required (cleavage after lysine or arginine residues); one missed cleavage was allowed; carbamidomethylation (C) was set as a fixed modification; and oxidation (M), deamidation (NQ) were set as variable modifications. The mass tolerance was set to $5 \mathrm{ppm}$ for precursor ions and $0.5 \mathrm{Da}$ for fragment ions. Results from the database search were imported into Progenesis, with mapping of peptide identifications to MS1 features. Quantitative data analysis of global proteomics was carried out as previously described. ${ }^{23}$ Briefly, label-free protein quantification was performed using the $\mathrm{Hi} / \mathrm{Hi} 2$ method. ${ }^{24}$ This approach uses the sum of signal intensities of the three (Hi3) or two (Hi2) best ionizing unique peptides of any given protein relative to the sum of signal intensities of the three (Hi3) or two (Hi2) best ionizing unique peptides of a reference protein (in this case ATP1A1 or ABCB1) quantified using MRM. Percentage identical peptides (PIP) and percentage identical proteins (PIPr) were estimated as previously described. ${ }^{20}$

For MRM analysis, all peak integration and review were performed using Skyline and results were subsequently exported to Microsoft Excel 2010 for quantitative calculations. Protein quantification data are provided in Table ES3 and ES6.

Using LC-Orbitrap MS data, Accurate Mass and Retention Time (AMRT) method was performed as a second targeted proteomic approach to quantify transporters within 
human brain microvessels. This approach is based on the peptide intensity in the MS spectrum by using the accurate mass measurement and corresponding retention time for a peptide signal. The ion peak intensity of the heavy and light versions of the same peptide are compared across samples and the relative abundance of the parent protein is inferred from the intensity ratios. ${ }^{25}$

\section{Sub-cellular localization and functional analysis}

Protein data annotation for sub-cellular localization was done by database search against UniProtKB (http://www.uniprot.org/), the Gene Ontology Project (GO, http://geneontology.org/) and the Human Protein Atlas (HPA, https://www.proteinatlas.org/). The PANTHER (Protein ANalysis THrough Evolutionary Relationships) classification system version 12.0 (http://www.pantherdb.org/) was used for bioinformatics analysis of all identified proteins to assign protein class and molecular function. ${ }^{26}$

\section{Statistical data analysis}

For the three sample sets, the abundance data were described as mean $\pm \mathrm{SD}$, coefficients of variation (CV), and fold difference (maximum/minimum). Normality of distribution was assessed and outliers were identified using iterative Grubbs' test using a cutoff $p$-value of 0.01 . Statistical difference between mean values of healthy and disease sets was determined by ANOVA analysis followed by post-hoc unpaired $t$-test. The $p$-value for significance was set at 0.05 , and Bonferroni-corrected for multiple tests (0.025). Principal coordinates/components analysis (PCA) and hierarchical cluster analysis (HCA) were performed using combined data from each sample and relationships were computed using Euclidian distance between samples and Spearman correlation (Rs) between genes. For intercorrelations, $\mathrm{Rs}>0.60$ and $\mathrm{R}^{2}>0.30$ and a Bonferroni-corrected $\mathrm{p}$-value of $<0.004$ were considered for significant correlations taking into account the effect of the units of 
measurement ${ }^{23}$ Graphs were generated using GraphPad Prism version 7.04/7.0c for Windows (GraphPad Software, San Diego, California, USA) and R version 3.1.0.

\section{RESULTS}

\section{Isolation of human brain microvessels}

Microvessels isolation was performed according to our previous published method ${ }^{20}$ with additional new steps to optimize for human (as opposed to rat) tissue; the use of a $20 \mu \mathrm{m}$ nylon mesh instead of $100 \mu \mathrm{m}$ and $20 \mu \mathrm{m}$ mesh sizes for crude microvessel extraction was adopted to remove small contaminants. We also introduced a focused-ultrasonicator step to shear the membrane and liberate proteins; this sonicator provides additional energy and temperature control over traditional low frequency laboratory sonicators. We measured protein concentration following sonication using the BCA assay and compared the results to those obtained using a traditional laboratory sonicator. We found the protein concentration was higher and more reproducible when using the focused sonicator compared with the traditional laboratory sonicator. Our optimized steps may overcome some of the difficulties of isolation of microvessels from human tissue. Figure 1A shows the experimental workflow followed in this study.

\section{Characterisation of the quality of isolated microvessels by LC-MS/MS}

To confirm the enrichment and purity of the isolated microvessels, the absolute protein expression of cell-specific markers of endothelial cells (GLUT1, PECAM1 and VWF), astrocytes (GFAP), neurons (SYP) and pericytes (CSPG4/NG2) were measured using quantitative global and MRM approaches. Based on the quantification values, the expression of endothelial markers ranged from high (GLUT1 between $4.05-57.8 \mathrm{pmol} / \mathrm{mg}$ protein) to medium/low abundance (VWF, 0.39-9.65 $\mathrm{pmol} / \mathrm{mg}$ protein; PECAM1, 0.30-1.67 pmol/mg protein). GLUT1 protein was highly expressed in the microvessels, and levels of the pericyte marker (CSPG4/NG2) and neuron marker (SYP) were very low in all the 22 samples. The 
second highest marker abundance (after GLUT1) was recorded for the GFAP marker, representing contamination by astrocyte endfeet, which form an integral part of the neurovascular unit and are extremely difficult to remove without extensive loss of endothelial cells (Table ES3, ES6 and Table 1).

Upon assessing the fold enrichment based on ATPase activity (commonly used as a marker for membranes) in microvessels and homogenates, the average enrichment was approximately 7.9-fold (Table ES7), suggesting efficient extraction of microvascular proteins from brain tissue homogenates.

\section{Untargeted quantification of BBB transporters}

To our knowledge, this is the first global proteomic study aimed at analysing human SLCs and ABC transporters in order to obtain a global view of the proteome dynamics, and a comparison between healthy and disease datasets. Following this strategy, approximately 5,000 proteins were identified from an average of 23,043 peptide matches per nanoLCMS/MS run. The initial output from Progenesis included many duplicated entries because several databases were used. A 'razor' was applied within Excel until each protein remaining contained at least one peptide unique to the data sheet. A 'razor' in proteomic terms assigns shared peptides to the most likely proteins in order to avoid or minimize assumptions in identification. ${ }^{27}$ After applying the razor, the average number of proteins was found to be 4,697, which was refined by exclusion of proteins with no unique peptide sequences against the proteome, truncated proteins and cDNA sequences, to 3,390 proteins. This was to ensure that only functional proteins with confirmed identification were used in the analysis. The global analysis demonstrated no significant difference in the quality of profiles of healthy and disease tissue. The PIPr (percentage identical proteins) and PIP (percentage identical peptides) between the samples were calculated and were found to range within $51-78 \%$ and $32-60 \%$, respectively. In this global study, the $\mathrm{Hi} 3 / \mathrm{Hi} 2$ peptide ion intensities (calculated as a 
mean) were used for quantification of endogenous and drug transporters. The criteria used for protein inclusion in the study included selection of only peptides identified as unique with high scores $(>15)$, with proteins identified with only one unique peptide being considered as supporting evidence for transporter expression. Several transporters were found in fewer than 10 samples (Table ES2), these transporters were only considered for identification and quantification if their identified peptides met the applied criteria. In Table ES3, proteins were quantified based on the plasma membrane marker, ATP1A1, as a reference for normalization of data generated using the Mascot search engine. A second reference protein, ABCB1 (MDR1), was then used to confirm the results. The global analysis was able to generate abundances similar to MRM targeted quantification (Tables ES3 and ES6) in this study except for a few low abundance transporters. Others have observed the same trend. ${ }^{17,28}$ Agreement between methods used in this study is confirmed by Figure 1B and C.

\section{Novel drug and endogenous transporters identified and quantified using the global approach}

Out of the 77 proteins (14 ABC, 52 SLC and 11 cell markers, i.e. receptors and tight junction proteins) (Table ES3) identified and quantified using the global approach, 37 proteins (ABCA2, $\mathrm{ABCA} 8, \mathrm{ABCA} 9, \mathrm{ABCB} 1, \mathrm{ABCG} 2, \mathrm{ABCC} 3, \mathrm{ABCC} 4, \mathrm{ABCC}$, SLC1A2, SLC1A3, SLC1A4, SLC1A5, SLC3A2, SLC6A6, SLC6A12, SLC6A13, SLC7A1, SLC7A5, SLC16A1, SLC19A1, SLC27A4, SLC47A1, SLC51A, SLC51B, SLCO1A2, SLCO2B1, SLCO3A1, SLC2A1, PECAM1, VWF, GFAP, GSPG4, SYP, LRP1, TFR1, INSR and CLDN5) were identified and quantified in earlier studies based on mRNA expression profiling and MRM analysis in human brain microvessels. ${ }^{17,28}$ We have identified an additional 39 human ABC/SLC transporters. 20 of these (ABCB9, ABCE1, ABCF1, ABCF2, SLC1A6, SLC1A7, SLC2A13, SLC4A10, SLC8A3, SLC9A2, SLC9A6, SLC12A4, SLC12A6, SLC14A1, SLC16A2, SLC27A1, SLC30A1, SLC33A1, SLC38A5, SLC41A3) 16 
were identified only, and 19 (ABCD3, ABCF3, SLC4A1, SLC4A4, SLC6A1, SLC6A7, SLC6A11, SLC8A1, SLC8A2, SLC9A3R1, SLC9A3R2, SLC12A2, SLC12A7, SLC17A7, SLC30A3, SLC38A3, SLC39A10, SLC44A1, SLC44A2) were also quantified for the first time in this study by label-free analysis in human brain microvessels. Table ES3 lists novel and previously identified and quantified SLC/ABC transporters, cell markers, receptors and tight junction proteins, with relevant references to other complementary data from targeted studies.

\section{Accurate Mass and Retention Time (AMRT) methodology}

The AMRT-based targeted method ${ }^{25}$ for protein quantification was used to measure five transporters (ABCB1, ABCG2, SLC22A3, SLC51A, SLCO1A2) and one plasma protein marker ATP1A1 (Table S2) using one peptide each for the transporters and two peptides for ATP1A1. Importantly, we found that the average abundance values of five transporters and plasma membrane marker levels showed a strong and statistically significant correlation (Figure S2A) between AMRT and MRM approaches with $\mathrm{R}^{2} \geq 0.99$. Supplementary Table ES4 shows AMRT data for individual donors.

Technical reproducibility was evaluated by measuring the abundances of ABCB1, ABCG2, SLC22A3, SLC51A, SLCO1A2 and ATP1A1 in three samples (one dementia and two healthy individuals) using the AMRT approach with QconCAT peptides used as standard. The technical variability represented as a relative error was $\% \mathrm{RE}<30 \%$, with fold errors of less than 1.33 for the transporters abundances between all the 3 samples analysed (Figure S2B, Supplementary Table ES5); this suggests that there is a very low variability between the two technical replicates.

\section{Gene ontology and functional enrichment of proteins in human brain microvessels}

The identified proteins $(3,390$ in total) were annotated for sub-cellular location and protein class by analysing gene names against GO, UniProt, HPA and PANTHER databases 
(Figure 2A, B). Based on these results, 19\% of proteins were assigned to the plasma membrane; $36 \%$ and $22 \%$ were identified as belonging to cytoplasm and nucleus, respectively. Proteins from endoplasmic reticulum, Golgi body and mitochondria represented $11 \%, 3 \%$ and $10 \%$ of identified proteins, respectively. It is worth noting that several proteins can be found in multiple subcellular locations. Figure 2B shows assignment of proteins based on protein class, in which the majority of proteins were classified as nucleic acid binding proteins (321 proteins), hydrolases (284 proteins), enzyme modulators (282 proteins), and cytoskeletal proteins (191 proteins). Importantly, 131 proteins were identified as transporters, out of which $\mathrm{ABC}$ transporters and SLCs represented 13\% and 46\%, respectively (Figure 2C).

\section{Microvessel protein content and its variability}

The values of BMvPGB in the 22 samples formed a normal distribution $(p=0.05)$, with minimum and maximum values of 0.19 and $0.76 \mathrm{mg}$ microvessel protein per gram brain tissue, respectively, representing a 4-fold variation. The mean BMvPGB content \pm SD was $0.44 \pm 0.15 \mathrm{mg} / \mathrm{g}$ brain (Table ES7). Variation in BMvPGB content was assessed by brain donor gender and age and analyzed by unpaired $t$-test and Spearman correlation, respectively. BMvPGB contents were not associated with gender $(\mathrm{n}=15$ male and $\mathrm{n}=7$ female; $p>0.05)$ and no correlation was observed between protein content and age (average donor age of 78 years). Dementia (DLB and AD) had no significant effect on BMvPGB levels (unpaired $t$ test, $p>0.05$ ). Figure 2D shows the BMvPGB content and level of enrichment for each sample.

\section{Membrane expression levels of transporters and markers in isolated human brain microvessels}

Table 1 summarizes the protein expression levels of the most important membrane transporters for drug and endogenous disposition. The measured proteins included 20 
membrane transporter proteins and 6 cell markers in isolated microvessels fractions. The quantification was performed by means of multiplexed MRM/SRM with the same specific peptides from the Liver TransCAT used in our previous report ${ }^{18}$ and with new peptides from the Brain TransCAT as shown in Table ES1. One membrane protein (ABCC1) was below the lower limit of quantification (Table ES6) estimated at $0.01 \mathrm{pmol} / \mathrm{mg}$ protein and determined as the protein amount that would produce less than 5000 count of peak area in the chromatogram when sample protein is measured by LC-MS/MS.

For MRM analysis, technical replication was based on three analyses with Liver TransCAT, Brain TransCAT or both TransCATs used as standards. These preparations were analyzed only once each. Several quality controls were applied at the data analysis stage to ensure that only reliably quantified transporters are included. For transporters quantified in duplicate, the technical variability measured as a relative error (\%RE) was shown to be within 40\%, except OATP1B3 which was within 42\%. Three transporters (SLC7A5, SLC22A1 and SLCO2B1) were quantified using two peptides, and the results were within 1.2 fold (Supplementary Table ES6).

$\mathrm{ABCB} 1, \mathrm{ABCG} 2$ and the $\mathrm{ABCC}$ family are considered to be the most important efflux transporters implicated in drug resistance. ${ }^{29} \mathrm{ABCB} 1 / \mathrm{MDR} 1$ and ABCG2/BCRP were the most abundant $\mathrm{ABC}$ transporters (Figure 3B). ABCC6/MRP6 was also present, but at a much lower concentration than ABCB1/MDR1 (5.4-fold) and ABCG2/BCRP (4.6-fold). For SLCs, endothelial cell marker (SLC2A1/GLUT1) showed the most abundant expression indicating the enrichment of endothelial cells (Table 1, Figure 3A), while organic anion transporter 2 (SLC22A7/OAT2) and monocarboxylate transporter 1 (SLC16A1/MCT1) showed high variability between donors and were expressed in the range of 2.50-16.20 and $1.05-14.10 \mathrm{pmol} / \mathrm{mg}$ protein (Figure 3B). The quantities of the other SLC22 members (SLC22A1/OCT1, SLC22A3/OCT3, SLC22A6/OAT1, SLC22A8/OAT3 and 
SLC22A9/UST3) were in the range of $0.23-0.80 \mathrm{pmol} / \mathrm{mg}$ protein. SLC22A4/OCTN1 was expressed at $0.04 \mathrm{pmol} / \mathrm{mg}$ protein and this transporter was at the limit of quantification. The expression of OATPs transporters in brain samples was in the order of OATP1C1 > OATP2B1 > OATP1B3 > OATP1A2. Inter-individual variability was assessed based on fold change in transporter abundance. Transporter protein expression showed considerable biological variability with a CV in a range of 19\%-100\% except for ABCC6/MRP6, SLC22A3/OCT3, SLC22A8/OAT3, SLCO2B1/OATP2B1 and SLCO1C1/OATP1C1, which were less variable with CV values of $11.5 \%-14.8 \%$. The protein expression levels of specific cell markers such as PECAM1 (endothelial cells), NG2 (pericytes), GFAP (astrocytes), and SYP (neurons) and the plasma membrane marker $\mathrm{Na}^{+} / \mathrm{K}^{+-} \mathrm{ATPase}$ were measured in the ranges $0.30-1.67,0.08-0.24,2.88-65.3,0.40-6.56$ and $3.77-78.7 \mathrm{pmol} / \mathrm{mg}$ total protein, respectively. The GFAP and $\mathrm{Na}^{+} / \mathrm{K}^{+-}$ATPase cell markers exhibited the greatest interindividual differences in protein expression, with a 22.7 and 20.9-fold difference for GFAP and $\mathrm{Na}^{+} / \mathrm{K}^{+-}$ATPase between the donors with the highest and lowest levels, respectively. Detailed MRM quantification data are provided in Table ES6. 
Table 1: Protein expression levels of plasma membrane marker, SLCs, ABC transporters, and cell markers for endothelial cells, pericytes, neurons, and astrocytes ( $\mathrm{pmol} / \mathrm{mg}$ total protein) in Healthy and disease brain microvessel samples. Data are expressed as mean $\pm \mathrm{SD}$; ULQ, under limit of quantification; NQ, not quantified; $n$, the number of brain samples with measurements above the limit of quantification. * represents abundance from two replicates

\begin{tabular}{|c|c|c|c|c|c|c|c|c|c|}
\hline \multicolumn{10}{|c|}{ Absolute protein expression level (means \pm SD, pmol/mg total protein) } \\
\hline \multirow{2}{*}{ Alias/Gene name } & \multirow{2}{*}{ Surrogate peptide used } & \multicolumn{6}{|c|}{ The present study } & $\begin{array}{l}\text { Uchida et al., } \\
2011(n=7)\end{array}$ & \multirow{2}{*}{$\begin{array}{c}\begin{array}{c}\text { Shawhana et al., } \\
2011(\mathrm{n}=5)\end{array} \\
\text { Healthy }\end{array}$} \\
\hline & & Healthy & $\mathbf{n}$ & DLB & $\mathbf{n}$ & AD & $\mathbf{n}$ & Healthy & \\
\hline \multicolumn{10}{|c|}{ Transporters } \\
\hline $\mathrm{ABC} 2 / \mathrm{ABCA} 2$ & LGGNPLFR & $0.08 \pm 0.03$ & $\overline{12}$ & $0.08 \pm 0.03$ & 5 & $0.09 \pm 0.03$ & $-\overline{5}$ & $2.86 \pm 0.58$ & $2.11 \pm 0.78$ \\
\hline MRP1/ABCC1 & TPSGNLVNR & $\begin{array}{l}<0.05 \pm 0.05 \\
\quad \text { (ULQ) }\end{array}$ & 9 & $\begin{array}{l}<0.04 \pm 0.01 \\
\quad(\mathrm{ULQ})\end{array}$ & 3 & $\begin{array}{l}<0.06 \pm 0.03 \\
\quad \text { (ULQ) }\end{array}$ & 5 & $<0.211$ (ULQ) & $<0.21$ (ULQ) \\
\hline MRP5/ABCC5 & FFDTTPTGR & $\begin{array}{l}<0.01 \pm 0.002 \\
\quad(\mathrm{ULQ})\end{array}$ & 12 & $\begin{array}{l}<0.02 \pm 0.002 \\
\quad \text { (ULQ) }\end{array}$ & 5 & $\begin{array}{l}<0.01 \pm 0.002 \\
\quad \text { (ULQ) }\end{array}$ & 5 & $<0.497$ (ULQ) & $<0.5$ (ULQ) \\
\hline MRP6/ABCC6 & SSLPSALLGELSK & $0.48 \pm 0.06^{*}$ & 12 & $0.48 \pm 0.04^{*}$ & 5 & $0.47 \pm 0.07^{*}$ & 5 & $<0.174$ (ULQ) & $<0.17$ (ULQ) \\
\hline MDR1/ABCB1 & AGAVAEEVLAAIR & $2.58 \pm 0.93$ & 12 & $3.18 \pm 0.91$ & 5 & $2.25 \pm 1.48$ & 5 & $6.06 \pm 1.69$ & $3.98 \pm 0.88$ \\
\hline BCRP/ABCG2 & VIQELGLDK & $2.22 \pm 0.61^{*}$ & 12 & $2.31 \pm 0.63^{*}$ & 5 & $1.91 \pm 0.84^{*}$ & 5 & $8.14 \pm 2.26$ & $6.15 \pm 1.41$ \\
\hline \multicolumn{10}{|c|}{ SLC transporters } \\
\hline $\mathrm{OCT} 1 / \mathrm{SLC} 22 \mathrm{~A} 1$ & MLSLEEDVTEK & $0.58 \pm 0.11^{*}$ & 12 & $0.55 \pm 0.10^{*}$ & 5 & $0.44 \pm 0.09^{*}$ & 5 & $<0.288$ (ULQ) & $<0.29$ (ULQ) \\
\hline OCT1/SLC22A1 & GVALPETMK & $0.54 \pm 0.06^{*}$ & 12 & $0.56 \pm 0.07^{*}$ & 5 & $0.45 \pm 0.17^{*}$ & 5 & & \\
\hline ОСТ3/SLC22A3 & GIALPETVDDVEK & $0.62 \pm 0.08^{*}$ & 12 & $0.66 \pm 0.08^{*}$ & 5 & $0.59 \pm 0.11^{*}$ & 5 & $<0.207$ (ULQ) & $<0.21$ (ULQ) \\
\hline OCTN1/SLC22A4 & AFILDLFR & $\begin{array}{l}<0.04 \pm 0.01 \\
\quad(\mathrm{ULQ})\end{array}$ & 12 & $\begin{array}{l}<0.02 \pm 0.02 \\
\quad(\mathrm{ULQ})\end{array}$ & 5 & $\begin{array}{l}<0.02 \pm 0.02 \\
\quad(\mathrm{ULQ})\end{array}$ & 5 & $<0.123$ (ULQ) & $<0.12$ (ULQ) \\
\hline OAT1/SLC22A6 & TSLAVLGK & $0.48 \pm 0.11$ & 12 & $0.48 \pm 0.07$ & 5 & $0.64 \pm 0.07$ & 5 & $<0.909$ (ULQ) & $<0.91$ (ULQ) \\
\hline $\mathrm{OAT} 2 / \mathrm{SLC} 22 \mathrm{~A} 7$ & WLLTQGHVK & $7.90 \pm 3.80$ & 8 & $9.92 \pm 3.70$ & 5 & $6.95 \pm 2.53$ & 4 & $<0.153$ (ULQ) & $<0.15$ (ULQ) \\
\hline OAT3/SLC22A8 & LSLEELK & $0.27 \pm 0.03$ & 12 & $0.26 \pm 0.02$ & 5 & $0.24 \pm 0.01$ & 5 & $<0.348$ (ULQ) & $<0.35$ (ULQ) \\
\hline OAT7/SLC22A9 & DTLTLEILK & $0.51 \pm 0.10^{*}$ & 12 & $0.48 \pm 0.03 *$ & 5 & $0.46 \pm 0.11^{*}$ & 5 & $<0.326$ (ULQ) & $<0.33$ (ULQ) \\
\hline ENT1/SLC29A1 & WLPSLVLAR & $0.27 \pm 0.10$ & 12 & $0.22 \pm 0.09$ & 5 & $0.24 \pm 0.04$ & 5 & $0.568 \pm 0.134$ & $0.86 \pm 0.13$ \\
\hline LAT1/SLC7A5 & GDVSNLDPNFSFEGTK & $0.59 \pm 0.15$ & 12 & $0.74 \pm 0.09$ & 5 & $0.56 \pm 0.14$ & 5 & $0.431 \pm 0.091$ & $0.80 \pm 0.25$ \\
\hline LAT1/SLC7A5 & SADGSAPAGEGEGVTLQR & $0.71 \pm 0.25$ & 9 & $0.90 \pm 0.29$ & 5 & $0.55 \pm 0.01$ & 3 & & \\
\hline OATP1/SLCO1A2 & EGLETNADIIK & $0.54 \pm 0.10^{*}$ & 12 & $0.50 \pm 0.04^{*}$ & 5 & $0.47 \pm 0.11^{*}$ & 5 & $<0.695$ (ULQ) & $<0.69$ (ULQ) \\
\hline OST- $\alpha /$ SLC51A & YTADLLEVLK & $0.45 \pm 0.13$ & 12 & $0.50 \pm 0.09$ & 5 & $0.43 \pm 0.14$ & 5 & $<0.292$ (ULQ) & $<0.29$ (ULQ) \\
\hline OATP8/SLCO1B3 & NVTGFFQSLK & $0.46 \pm 0.15$ & 12 & $0.58 \pm 0.13$ & 5 & $0.52 \pm 0.20$ & 5 & $<0.572$ (ULQ) & $<0.57$ (ULQ) \\
\hline OATP2B1/SLCO2B1 & IGPAGEVPQVPDK & $0.40 \pm 0.04^{*}$ & 12 & $0.36 \pm 0.03$ & 5 & $0.35 \pm 0.02$ & 5 & $<0.337$ (ULQ) & $<0.34(\mathrm{NQ})$ \\
\hline OATP2B1/SLCO2B1 & SSPAVEQQLLVSGPGK & $0.48 \pm 0.11^{*}$ & 12 & $0.36 \pm 0.03$ & 5 & $0.38 \pm 0.02$ & 5 & & \\
\hline OATP1C1/SLCO1C1 & DFLPSLK & $0.27 \pm 0.03$ & 12 & $0.28 \pm 0.02$ & 5 & $0.26 \pm 0.04$ & 5 & $<0.208$ (ULQ) & $<0.21$ (ULQ) \\
\hline \multicolumn{10}{|c|}{ Markers } \\
\hline \multicolumn{10}{|l|}{ Endothelial Markers } \\
\hline $\begin{array}{l}\text { GLUT1/SLC2A1 } \\
\text { PECAM1 }\end{array}$ & $\begin{array}{l}\text { TFDEIASGFR } \\
\text { IYDSGTYK }\end{array}$ & $\begin{array}{l}21.9 \pm 9.80 \\
0.89 \pm 0.46\end{array}$ & $\begin{array}{l}11 \\
12\end{array}$ & $\begin{array}{l}36.2 \pm 14.9 \\
0.82 \pm 0.15\end{array}$ & 5 & $\begin{array}{l}17.6 \pm 13.4 \\
0.52 \pm 0.13\end{array}$ & $\begin{array}{r}-5 \\
5\end{array}$ & $\begin{array}{c}139 \pm 46 \\
\mathrm{NQ}\end{array}$ & $\begin{array}{l}78.5 \pm 23 \\
1.57 \pm 0.21\end{array}$ \\
\hline \multicolumn{10}{|c|}{ Plasma membrane marker } \\
\hline \multirow[t]{2}{*}{$\mathrm{Na}+/ \mathrm{K}+\mathrm{ATPase}$} & IVEIPFNSTNK & $\overline{9.02} \pm \overline{5} . \overline{64} *$ & $-\overline{12}$ & $8.06 \pm 3.27^{*}$ & 5 & 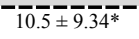 & -5 & $35.1 \pm \overline{12.6}$ & $20.8 \pm 6.5$ \\
\hline & NPNTSEPQHLLVMK & $17.5 \pm 16.2$ & 12 & $16.8 \pm 5.92$ & 5 & $22.1 \pm 28.4$ & 5 & & \\
\hline \multicolumn{10}{|l|}{ Astrocyte marker } \\
\hline \multicolumn{10}{|l|}{ Pericyte marker } \\
\hline \multirow[t]{2}{*}{$\mathrm{NG} 2$} & APLEVPQALGR & $0.15 \pm 0.06$ & 12 & $0.12 \pm 0.06$ & 5 & $0.12 \pm 0.03$ & $-\overline{5}$ & NQ & $1.07 \pm 0.41$ \\
\hline & LVLGQEEERR_- & $0.11 \pm 0.05$ & 12 & - $0.18 \pm 0.05$ & 5 & $0.14 \pm 0.06$ & 5 & & \\
\hline \multicolumn{10}{|l|}{ Neuron marker } \\
\hline SYP & ETGWAAPFLR & $3.01 \pm 2.45$ & 12 & $1.95 \pm 1.20$ & 5 & $3.11 \pm 2.04$ & $-\overline{4}$ & $\mathrm{NQ}$ & $1.45 \pm 0.37$ \\
\hline
\end{tabular}




\section{Comparison of membrane protein expression levels in isolated human brain microvessels with previous studies}

Table 1 shows a comparison of abundance means of 22 transporters and 6 markers in the present 22 samples with those in a targeted analysis of 12 individual samples as previously reported by Terasaki and co-workers. ${ }^{17,28}$ In the MRM analysis, one additional membrane protein $(\mathrm{CDH} 17)$ was quantified for the first time in this study. Only 5 transporters and 6 markers were successfully quantified by both groups, and the mean abundances were in the same range with typically a factor of 2-4 difference. Working in 2011 , Terasaki and co-workers ${ }^{17,28}$ found many of the transporter peptides to be below the limit of quantification. In general, they reported higher levels of cell markers than in the present study, reflecting different sample preparations. At this stage, it is not possible to determine whether the differences in the two studies were due to biological factors, tissue handling and storage, or sample preparation.

Using different proteotypic peptides as well as different sample preparation methods can affect protein quantification, and this can explain some of the differences in reported values (Table ES3).

\section{$\mathrm{ABC}$ and SLC transporter-transporter correlation of blood-brain barrier protein expression}

Transporter-transporter correlation analysis (intercorrelation analysis) was performed on abundance data generated by targeted proteomics. In particular, the transporter pairs ABCB1/ABCG2, SLC22A9/SLCO1A2, SLC22A9/SLC51A, SLCO1A2/SLC51A and SLC2A1/SLC7A5 showed very strong correlation $(R s=0.81-0.94, p<0.0001, R 2=0.58-0.93)$. ABCB1 and ABCG2 showed a significant and strong correlation with endothelial cell marker SLC2A1 $(\mathrm{Rs}=0.80, \mathrm{p}<0.0001, \mathrm{R} 2=0.55 ; \mathrm{Rs}=0.71, \mathrm{p}=0.0003, \mathrm{R} 2=0.50$, respectively). Amino 
acid transporter SLC7A5 expression was significantly correlated with several markers; such correlations included PECAM1 $(\mathrm{R} s=0.64, \mathrm{p}=0.001, \mathrm{R} 2=0.31)$. We also tested a potential association between ATP1A1 expression and transporters. We found expression levels of ATP1A1 to be associated with ABCC6, SLC22A1, SLC22A9, SLCO1A2 and SLC51A expression. The matrix in Figure 4 shows the most significant correlations between SLCs, ABC transporters and cell markers quantified.

\section{Covariates of proteome expression at the blood-brain barrier}

Trends of similarity of proteome expression profiles at the BBB between samples were assessed using percentage identical peptides (PIP) and percentage identical proteins (PIPr) data for the 22 samples. Principal coordinates analysis (PCoA) and hierarchical cluster analysis (HCA) were performed both at the protein and peptide levels and the results were very similar at the two levels (Figure 5) with samples from relatively young healthy donors clutering mainly in the middle with samples from patients with DLB. (Note that the blue ellipse refers to DLB donors only - the cluster is assessed visually, and can be deemed to include patient 3.) Samples from $\mathrm{AD}$ patients tended to scatter around the cluster (only patient 12 is within the cluster). Four normal donors are also outside the cluster; three of these were very elderly (87, 89 and 90) at the time of death, but patient 2 was only 54. Note, however, that there is no clustering of these outlier individuals; they are as different from one another as from the main cluster. This suggests that the main covariates of protein expression at the BBB in this dataset were the disease state and age, with some healthy donors of very old age behaving like AD patients.

\section{Covariates of transporter protein expression at the blood-brain barrier}

Transporter expression profiles at the BBB were assessed using principal components analysis (PCA) and hierarchical cluster analysis (HCA) applied to a heatmap of abundance data 
(Figure 6). The PCA analysis data were confirmatory of global proteome profiles; older healthy individuals (donors 2, 9, 14, 17, 18 and 22) with average age $82.3 \pm 14.1$ years, behaving like $\mathrm{AD}$ patients, whereas younger healthy donors tended to cluster in the middle $(75.2 \pm 15.0$ years). With the exception of sample 12, none of the AD samples clustered with the healthy ones, which is a similar trend to the global proteomic analysis. HCA confirmed the cluster and outliers in the PCA and the heatmap showed correlations of expression between drug transporters (MDR1 and BCRP) and SLCs of endogenous compounds, including glucose and organic cations/anions (SLC2A1/SLC7A5 and SLCO1A2/SLC22A9) (Figure 6C). PCA analyses using data from different replicates and different peptides (where available) were confirmatory. This reflects that disease, age and inter-correlation of gene expression represent significant factors that can affect the transporter make-up of the BBB.

\section{Inter-species differences between rat and human BBB transporter/receptor expression levels}

In-house data for human (Table 1 and Table ES3) and rat ${ }^{20}$ were used to determine comparative levels of transporters and receptors between rat and human brain capillaries. Figure 7A shows similarities and differences in expression levels, where several transporters (NKCC1, AE1, MCT1, BCRP, EAAT2), receptors (LRP1, TfR1), tight junction and marker proteins (CLDN5, ATP1A1) were within 2-fold. Higher expression levels in rat microvessels were observed for MDR1, EAAT1, LAT1, CAT1, PMP70 and the glucose transporter GLUT1. This is in overall agreement with literature on comparative data between rats and humans ${ }^{30}$ as shown in Figure $7 \mathrm{~B}$. 


\section{DISCUSSION}

Precision dosing, ${ }^{31}$ in which the amount and frequency of drug dosing is tailored to individual patients, can be critical to the outcome of therapy. Precision dosing depends upon understanding the efficacy and toxicity of any drug targeting the individual brain, which is dependent on the concentration at the site of action, and in turn, on the abundance and activity of drug transporters at the BBB. ${ }^{32} \mathrm{We}$ describe the first systematic study, using a quantitative strategy combining both targeted and global methodology, of the proteomic make-up of the $\mathrm{BBB}$, focussing on drug and endogenous transporters. The 22 brains analysed (15 males, 7 females) had an average age of 78 years (range: 53-91 years), and were classified into three different sub-groups: healthy brains (12 samples), brains from Alzheimer's patients (5 samples) and brains from patients with dementia with Lewy bodies ( 5 samples).

To isolate the microvessels of the BBB, we used an optimized methodology previously performed and validated in a rat brain model $^{20}$ with minor modifications to sample preparation from frozen brain cortical samples. Differences may be expected when different types of tissue samples (i.e. fresh compared to frozen), storage conditions or sample preparation methods are used. ${ }^{33}$ The average enrichment of microvessels was very high $(>7.9$ fold), and the purity of microvessels was assessed using brain cell-specific markers. Astrocyte endfeet tend to be tightly bound to the neurovascular unit, making it very difficult to remove them entirely. The neuron marker SYP and pericyte marker NG2 were also detected but consistently at very low levels.

The quality of the sample preparation was key to our being able to detect and quantify 19 previously undetected transporters and to detect (but not quantify) a further 20 . In total, 22 transporters were quantified using a targeted strategy and 31 using the global, untargeted strategy showing the value of using both methods. 16 of the proteins detected by the targeted approach fell below the limit of quantification of the global proteomic experiment, but 32 additional 
transporters were quantifiable by untargeted methods. For the more abundant transporters, the targeted and global methods returned very consistent values (Figure 1C). In the one case where the difference between targeted and global analysis was considerable, SLC7A5 (which is involved in high-grade gliomas), it seems probable that signal overlap gave rise to an overestimate in the label-free experiment, ${ }^{34}$ consistent with previous reports. ${ }^{17,28}$ Disease-related transporters quantified for the first time include choline transporter-like proteins 1 and 2, SLC44A1 and SLC44A2, reported to be involved in abnormal choline disposition associated with papillary glioneuronal tumors. ${ }^{35}$

In drug development, several scaling factors are used for the extrapolation of in vitro data to in vivo parameters to predict drug disposition across the $\mathrm{BBB}^{16}$, an approach which is starting to be accepted for supporting evidence in clinical trials by medicines regulatory agencies. ${ }^{36}$ One important scaling factor is the protein content of brain microvessels per gram tissue (BMvPGB). ${ }^{16,17}$ The corresponding liver and kidney scaling factors are well-established ${ }^{37,38}{ }^{37}$ but to date, modeling of drug disposition across the human BBB relies on a single study of six histologically healthy brains for this parameter. ${ }^{16,17}$ Our data for healthy brains shows limited overall variability (4-fold) with an average of $0.44 \mathrm{mg}$ protein/g brain. The previously reported values $^{17}$ show BMvPGB (0.244 mg protein/g brain) and 7-fold variability. The present study therefore trebles healthy brain data that can contribute to BBB models, allowing better description of population variability. The mean BMvPGB levels of AD and DLB donors (0.40 and $0.48 \mathrm{mg} / \mathrm{g}$ brain, respectively) were very similar to the levels of healthy donors. BMvPGB levels showed no correlation with age, sex or disease state.

Transporter expression data revealed a large degree of inter-individual variability across ABC (3- to 11-fold) and SLC (2- to 14-fold) transporters. The analyzed set of samples was from 
a small number of donors, which should be considered when using the generated data. Extending this study to cover a large number of samples from both health and disease populations should confirm these conclusions.

There were no significant univariate sex or age-related differences in the abundances of transporters, in line with recent data on liver transporters. ${ }^{39}$ The expression of four transporters, however, correlates significantly with disease (Figure 3). The most significant correlation $(\mathrm{p}<0.01)$ is the upregulation of SLC22A6 in Alzheimer's disease. This is a drug transporter responsible for influx of many drugs, including anti-virals and anti-inflammatory drugs to the brain. Multivariate analysis revealed general differences between patient sub-groups, with a set of donors, including all the DLB patients and most of the younger healthy individuals forming a defined cluster in the principal components analysis. Alzheimer's patients and several of the older healthy donors were outside this cluster. This suggests that age in healthy individuals and Alzheimer's disease in the disease population are the main contributors to differences in expression. This trend was identified in the global proteomic profiling of the blood-brain barrier at both the peptide and protein levels (Figure 5), as well as in the more specific analysis of transporter levels in brain endothelial cells (Figure 6). The expression trends shown for the first time in this study support recent guidelines advocating the definition of Alzheimer's disease by its biochemical fingerprint, compared to predominantly anatomically or clinically defined types of dementia, such as dementia with Lewy bodies. ${ }^{40}$

We also examined inter-species differences in expression between human and rat 30,20 (Figure 7). The rat is an important pre-clinical species and transport data based on rat need to be scalable to human. While some transporter abundances (e.g. BCRP) are clearly useful for 
translation (rat to human), others (such as MDR1) show large discrepancies throwing doubt on the suitability of the rat as a pre-clinical species where this transporter is critical.

The importance of considering relationships between the expression patterns of proteins involved in drug metabolism and disposition has been highlighted in clinical and simulated trials. $^{37,41}$ Inter-correlations between individual transporters in the brain were assessed in this dataset for the first time (Figure 4), revealing associations that can be attributed to common genetic regulatory mechanisms, supported by transcriptomic evidence. ${ }^{42}$ The present dataset uncovered several correlations, not only between drug transporters but also between transporters involved in brain homeostasis (e.g. glucose and amino acid carriers). One important example of expression co-regulation is the correlation between $\mathrm{ABCB} 1$ and $\mathrm{ABCG} 2$, and patients with Alzheimer's disease showed relatively lower expression levels of both transporters, although neither reached statistical significance in the univariate analysis (Figure 3).

\section{CONCLUSION}

This study described the protein composition of the blood-brain barrier and will be used to inform Quantitative System Pharmacology models of health and disease.

\section{ASSOCIATED CONTENT \\ Supplementary Information}

Table S1: Demographic and clinical information of brain donors

Table S2: Absolute protein expression levels in microvessels isolated from 22 brains

Table S3: Summary matrix of correlation analysis of ABC, SLC transporters and cell markers expression data

Table ES1: Peptide sequences included in brain TransCAT 
Table ES2: Summary of peptide and protein analysis by Progenesis after application of a Razor Table ES3. Protein quantification using label free in human brain microvessels

Table ES4: Summary of transporters and membrane marker quantified using accurate mass retention time (AMRT) approach

Table ES5: Technical variability between 3 brains for ABCB1, ABCG2, SLC22A3 transporters and ATP1A1 membrane marker using AMRT

Table ES6: Protein abundances in individual human brain microvessels determined using MRM approach

Table ES7: Protein activity and BMvPGB protein content estimate data in individual human brain donors

Figure S1: Assessment of correlation between ATPase activity and protein concentration in microvessels and homogenates from human brain tissue

Figure S2: Quality control assessment of accurate mass and retention time (AMRT) methodology with reference to multi-reaction monitoring (MRM)

Figure S3: Percentage identical peptides (PIP) and percentage identical proteins (PIPr) between the proteomes of the 22 brains

AUTHOR INFORMATION

Corresponding Authors

*Email: Zubida.al-majdoub@manchester.ac.uk

*Email: Jill.barber@manchester.ac.uk

$\underline{\text { ORCID }}$

Zubida M. Al-Majdoub: 0000-0002-1497-3140

Jill Barber: 0000-0002-5424-0291 


\section{CONFLICT OF INTEREST}

Sibylle Neuhoff and Amin Rostami-Hodjegan are employee of Certara UK Limited (Simcyp Division).

\section{AUTHOR CONTRIBUTIONS}

This study was designed by Zubida M. Al-Majdoub, Hajar Al Feteisi, Brahim Achour, Amin Rostami-Hodjegan and Jill Barber. Zubida M. Al-Majdoub, Hajar Al Feteisi and Stacey Warwood performed the experiments. Data analysis was performed by Zubida M. Al-Majdoub, Brahim Achour and Jill Barber. Zubida M. Al-Majdoub contributed new reagents. Zubida M. AlMajdoub, Brahim Achour, Sibylle Neuhoff, Amin Rostami-Hodjegan and Jill Barber contributed to the writing of the manuscript.

\section{FUNDING SOURECES}

This study was supported by the Simcyp (Certara) Grant and Partnership Scheme (GPS 2014/15).

\section{ACKNOWLEDGMENTS}

Tissue samples were supplied by The Manchester Brain Bank, which is part of the Brains for Dementia Research programme, jointly funded by Alzheimer's Research UK and Alzheimer's Society. The authors thank the Biological Mass Spectrometry Core Facility (Bio-MS), University of Manchester, for access to LC-MS/MS instrumentation and analysis software. 


\section{References}

(1) Abbott, N. J.; Romero, I. A. Transporting Therapeutics across the Blood-Brain Barrier. Molecular Medicine Today. 1996.

(2) Oby, E.; Janigro, D. The Blood-Brain Barrier and Epilepsy. Epilepsia. November 2006, pp 1761-1774.

(3) Abbott, N. J. Dynamics of CNS Barriers: Evolution, Differentiation, and Modulation. Cellular and Molecular Neurobiology 2005, 25 (1), 5-23.

(4) Ballabh, P.; Braun, A.; Nedergaard, M. The Blood-Brain Barrier: An Overview: Structure, Regulation, and Clinical Implications. Neurobiology of Disease 2004, 16 (1), 1-13.

(5) Ito, K.; Suzuki, H.; Horie, T.; Sugiyama, Y. Apical/Basolateral Surface Expression of Drug Transporters and Its Role in Vectorial Drug Transport. Pharmaceutical Research 2005, 22 (10), 1559-1577.

(6) Ohtsuki, S.; Terasaki, T. Contribution of Carrier-Mediated Transport Systems to the Blood-Brain Barrier as a Supporting and Protecting Interface for the Brain; Importance for CNS Drug Discovery and Development. Pharmaceutical Research. August 1, 2007, pp $1745-1758$.

(7) Insel, T. R. Next-Generation Treatments for Mental Disorders. Science Translational Medicine 2012, 4 (155), 1-10.

(8) Ringel, M.; Tollman, P.; Hersch, G.; Schulze, U. Does Size Matter in R\&D Productivity? If Not, What Does? Nature Reviews Drug Discovery. December 18, 2013, pp 901-902.

(9) Blennow, K.; de Leon, M. J.; Zetterberg, H. Alzheimer's Disease. The Lancet 2006, 368 
(9533), 387-403.

(10) Tomlinson, B. E.; Blessed, G.; Roth, M. Observations on the Brains of Non Demented Old People. Journal of Neurological Sciences 1968, 7, 331-356.

(11) Jensen, M.; Schroder, J.; Blomberg, M.; Engvall, B.; Pantel, J.; Ida, N.; Basun, H.; Wahlund, L.-O.; Werle, E.; Jauss, M.; et al. Cerebrospinal Fluid Abeta42 Is Increased Early in Sporadic Alzheimer's Disease and Declines with Disease Progression. Annals of Neurology 1999, 45 (4), 504-511.

(12) Montagne, A.; Zhao, Z.; Zlokovic, B. V. Alzheimer's Disease : A Matter of Blood - Brain Barrier Dysfunction? The Journal of Experimental Medicine. Journal of Experimental Medicine 2017, 214 (11), 3151-3169.

(13) Korolainen, M. A.; Goldsteins, G.; Alafuzoff, I.; Koistinaho, J.; Pirttilä, T. Proteomic Analysis of Protein Oxidation in Alzheimer's Disease Brain. Electrophoresis 2002, 23 (19), 3428-3433.

(14) Korolainen, M. A.; Goldsteins, G.; Nyman, T. A.; Alafuzoff, I.; Koistinaho, J.; Pirttilä, T. Oxidative Modification of Proteins in the Frontal Cortex of Alzheimer's Disease Brain. Neurobiology of Aging 2006, 27 (1), 42-53.

(15) Helms, H. C.; Abbott, N. J.; Burek, M.; Cecchelli, R.; Couraud, P.-O.; Deli, M. A.; Förster, C.; Galla, H. J.; Romero, I. A.; Shusta, E. V; et al. In Vitro Models of the Bloodbrain Barrier: An Overview of Commonly Used Brain Endothelial Cell Culture Models and Guidelines for Their Use. Journal of Cerebral Blood Flow \& Metabolism 2016, 36 (5), 862-890. 
(16) Gaohua, L.; Neuhoff, S.; Johnson, T. N.; Rostami-Hodjegan, A.; Jamei, M. Development of a Permeability-Limited Model of the Human Brain and Cerebrospinal Fluid (CSF) to Integrate Known Physiological and Biological Knowledge: Estimating Time Varying CSF Drug Concentrations and Their Variability Using in Vitro Data. Drug Metabolism and Pharmacokinetics 2016, 31 (3), 224-233.

(17) Uchida, Y.; Ohtsuki, S.; Katsukura, Y.; Ikeda, C.; Suzuki, T.; Kamiie, J.; Terasaki, T. Quantitative Targeted Absolute Proteomics of Human Blood-Brain Barrier Transporters and Receptors. Journal of Neurochemistry 2011, 117 (2), 333-345.

(18) Russell, M. R.; Achour, B.; Mckenzie, E. A.; Lopez, R.; Harwood, M. D.; RostamiHodjegan, A.; Barber, J. Alternative Fusion Protein Strategies to Express Recalcitrant QconCAT Proteins for Quantitative Proteomics of Human Drug Metabolizing Enzymes and Transporters. Journal of Proteome Research 2013, 12 (12), 5934-5942.

(19) Al-Majdoub, Z. M.; Carroll, K. M.; Gaskell, S. J.; Barber, J. Quantification of the Proteins of the Bacterial Ribosome Using QconCAT Technology. Journal of Proteome Research 2014.

(20) Al Feteisi, H.; Al-Majdoub, Z. M.; Achour, B.; Couto, N.; Rostami-Hodjegan, A.; Barber, J. Identification and Quantification of Blood-Brain Barrier Transporters in Isolated Rat Brain Microvessels. Journal of Neurochemistry 2018, 146 (6), 670-685.

(21) Wis, J. R.; Zougman, A.; Nagaraj, N.; Mann, M. Universal Sample Preparation Method for Proteome Analysis. 2009.

(22) MacLean, B.; Tomazela, D. M.; Shulman, N.; Chambers, M.; Finney, G. L.; Frewen, B.; 
Kern, R.; Tabb, D. L.; Liebler, D. C.; MacCoss, M. J. Skyline: An Open Source Document Editor for Creating and Analyzing Targeted Proteomics Experiments. Bioinformatics 2010, $26(7), 966-968$.

(23) Achour, B.; Al Feteisi, H.; Lanucara, F.; Rostami-Hodjegan, A.; Barber, J. Global Proteomic Analysis of Human Liver Microsomes: Rapid Characterization and Quantification of Hepatic Drug-Metabolizing Enzymes. Drug Metabolism and Disposition 2017, $45(6), 666-675$.

(24) Silva, J. C. Absolute Quantification of Proteins by LCMSE: A Virtue of Parallel Ms Acquisition. Molecular \& Cellular Proteomics 2005, 5 (1), 144-156.

(25) Silva, J. C.; Denny, R.; Dorschel, C. a; Gorenstein, M.; Kass, I. J.; Li, G.; Mckenna, T.; Nold, M. J.; Richardson, K.; Young, P.; et al. Quantitative Proteomic Analysis by Accurate Mass Retention Time Pairs. Analytical Chemistry 2005, 77 (7), 2187-2200.

(26) Mi, H.; Muruganujan, A.; Thomas, P. D. PANTHER in 2013: Modeling the Evolution of Gene Function, and Other Gene Attributes, in the Context of Phylogenetic Trees. Nucleic Acids Research 2013, 41 (D1), 377-386.

(27) Cox, J.; Mann, M. MaxQuant Enables High Peptide Identification Rates, Individualized p.p.b.-Range Mass Accuracies and Proteome-Wide Protein Quantification. Nature Biotechnology 2008, 26 (12), 1367-1372.

(28) Shawahna, R.; Uchida, Y.; Declèves, X.; Ohtsuki, S.; Yousif, S.; Dauchy, S.; Jacob, A.; Chassoux, F.; Daumas-Duport, C.; Couraud, P.-O.; et al. Transcriptomic and Quantitative Proteomic Analysis of Transporters and Drug Metabolizing Enzymes in Freshly Isolated 
Human Brain Microvessels. Molecular Pharmaceutics 2011, 8 (4), 1332-1341.

(29) Giacomini, K. M.; Huang, S.-M.; Tweedie, D. J.; Benet, L. Z.; Brouwer, K. L. R. R.; Chu, X.; Dahlin, A.; Evers, R.; Fischer, V.; Hillgren, K. M.; et al. Membrane Transporters in Drug Development. Nature Reviews Drug Discovery 2010, 9 (3), 215-236.

(30) Hoshi, Y.; Uchida, Y.; Tachikawa, M.; Inoue, T.; Ohtsuki, S.; Terasaki, T. Quantitative Atlas of Blood-Brain Barrier Transporters, Receptors, and Tight Junction Proteins in Rats and Common Marmoset. Journal of Pharmaceutical Sciences 2013, 102 (9), 3343-3355.

(31) Polasek, T. M.; Shakib, S.; Rostami-Hodjegan, A. Precision Dosing in Clinical Medicine: Present and Future. Expert Review of Clinical Pharmacology. August 3, 2018, pp 743746.

(32) Rostami-Hodjegan, A.; Tucker, G. T. Simulation and Prediction of in Vivo Drug Metabolism in Human Populations from in Vitro Data. Nature reviews. Drug discovery 2007, $6(2), 140-148$.

(33) Yousif, S.; Marie-Claire, C.; Roux, F.; Scherrmann, J. M.; Declèves, X. Expression of Drug Transporters at the Blood-Brain Barrier Using an Optimized Isolated Rat Brain Microvessel Strategy. Brain Research 2007, 1134 (1), 1-11.

(34) Achour, B.; Dantonio, A.; Niosi, M.; Novak, J. J.; Al-Majdoub, Z. M.; Goosen, T. C.; Rostami-Hodjegan, A.; Barber, J. Data Generated by Quantitative Liquid Chromatography-Mass Spectrometry Proteomics Are Only the Start and Not the Endpoint: Optimization of Quantitative Concatemer-Based Measurement of Hepatic Uridine-5'Diphosphate-Glucuronosyltransferase Enzymes with Ref. Drug Metabolism and 
Disposition 2018, 46 (6), 805-812.

(35) Soffietti, R.; Rudà, R.; Reardon, D. Rare Glial Tumors. In Handbook of Clinical Neurology; 2016; Vol. 134, pp 399-415.

(36) Shebley, M.; Sandhu, P.; Emami Riedmaier, A.; Jamei, M.; Narayanan, R.; Patel, A.; Peters, S. A.; Reddy, V. P.; Zheng, M.; de Zwart, L.; et al. Physiologically Based Pharmacokinetic Model Qualification and Reporting Procedures for Regulatory Submissions: A Consortium Perspective. Clinical Pharmacology and Therapeutics 2018, $104(1), 88-110$.

(37) Barter, Z. E.; Perrett, H. F.; Yeo, K. R.; Allorge, D.; Lennard, M. S.; Rostami-Hodjegan, A. Determination of a Quantitative Relationship between Hepatic CYP3A5*1/*3 and CYP3A4 Expression for Use in the Prediction of Metabolic Clearance in Virtual Populations. Biopharmaceutics and Drug Disposition 2010, 31 (8-9), 516-532.

(38) Scotcher, D.; Billington, S.; Brown, J.; Jones, C. R.; Brown, C. D. A. A.; RostamiHodjegan, A.; Galetin, A. Microsomal and Cytosolic Scaling Factors in Dog and Human Kidney Cortex and Application for In Vitro-In Vivo Extrapolation of Renal Metabolic Clearance. Drug Metabolism and Disposition 2017, 45 (5), 556-568.

(39) Prasad, B.; Evers, R.; Gupta, A.; Hop, C. E. C. A. C. a; Salphati, L.; Shukla, S.; Ambudkar, S. V.; Unadkat, J. D. Interindividual Variability in Hepatic Organic AnionTransporting Polypeptides and P-Glycoprotein (ABCB1) Protein Expression: Quantification by Liquid Chromatography Tandem Mass Spectroscopy and Influence of Genotype, Age, and Sex. Drug Metabolism and Disposition 2013, 42 (1), 78-88. 
(40) Jack, C. R.; Bennett, D. A.; Blennow, K.; Carrillo, M. C.; Dunn, B.; Haeberlein, S. B.; Holtzman, D. M.; Jagust, W.; Jessen, F.; Karlawish, J.; et al. NIA-AA Research Framework: Toward a Biological Definition of Alzheimer's Disease; Elsevier Inc., 2018; Vol. 14, pp 535-562.

(41) Doki, K.; Darwich, A. S.; Achour, B.; Tornio, A.; Backman, J. T.; Rostami-Hodjegan, A. Implications of Intercorrelation between Hepatic CYP3A4-CYP2C8 Enzymes for the Evaluation of Drug-Drug Interactions: A Case Study with Repaglinide. British Journal of Clinical Pharmacology 2018, 84 (5), 972-986.

(42) Wortham, M.; Czerwinski, M.; He, L.; Parkinson, A.; Wan, Y. J. Y. Expression of Constitutive Androstane Receptor, Hepatic Nuclear Factor 4 $\alpha$, and P450 Oxidoreductase Genes Determines Interindividual Variability in Basal Expression and Activity of a Broad Scope of Xenobiotic Metabolism Genes in the Human Liver. Drug Metabolism and Disposition 2007, 35 (9), 1700-1710. 

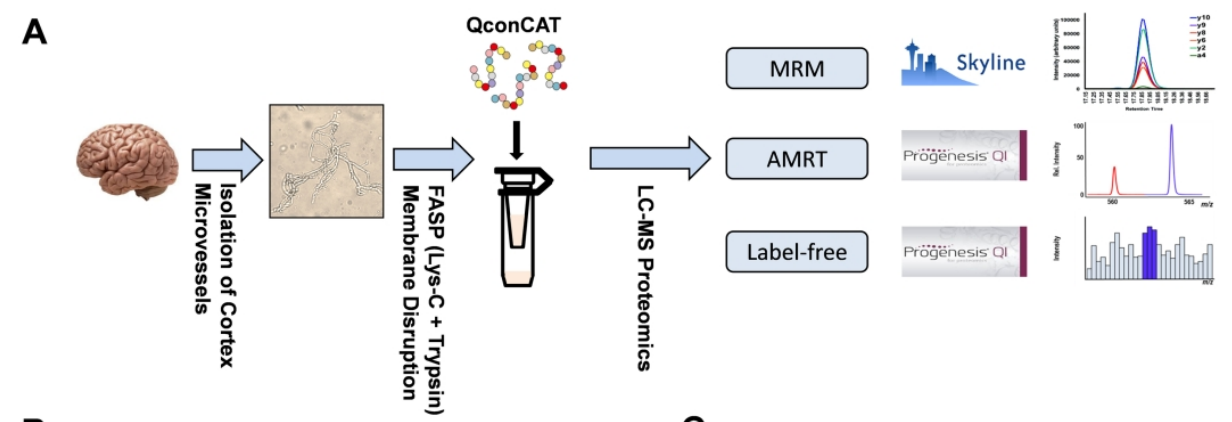

B

C
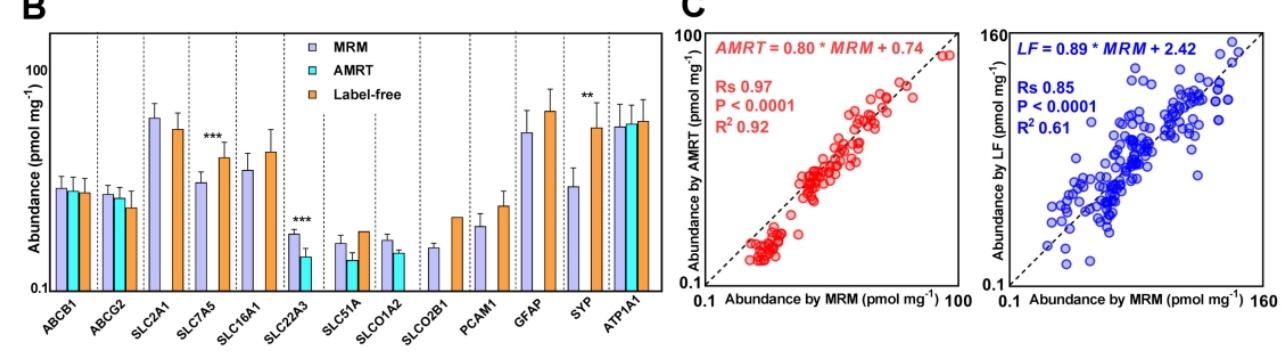

Figure 1: Brief experimental workflow and assessment of quantitative methods used to analyse the proteins expressed at the human blood-brain barrier. Several optimization steps (A) were introduced to isolate the microvessel fraction and extract membrane proteins, which were then proteolytically-digested and analysed using three LC-MS/MS proteomic methods: targeted multi-reaction monitoring (MRM), targeted accurate mass and retention time (AMRT) methodology, and label-free global proteomics using the two/three most abundant peptide peaks per protein. The assessment of transporter and marker proteins using the three methods showed limited differences between quantitative results $(B)$ and excellent overall correlation between data (C), with the label-free (LF) method being relatively less precise and accurate than the targeted MRM and AMRT methods. AMRT was used to measure five transporters (ABCB1, ABCG2, SLC22A3, SLC51A and SLCO1A2) and one plasma protein marker ATP1A1 in 22 brains.

$261 \times 159 \mathrm{~mm}(300 \times 300 \mathrm{DPI})$ 
A
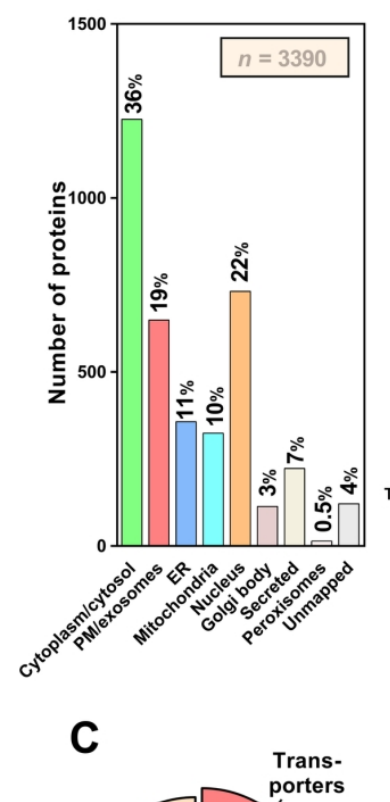

B

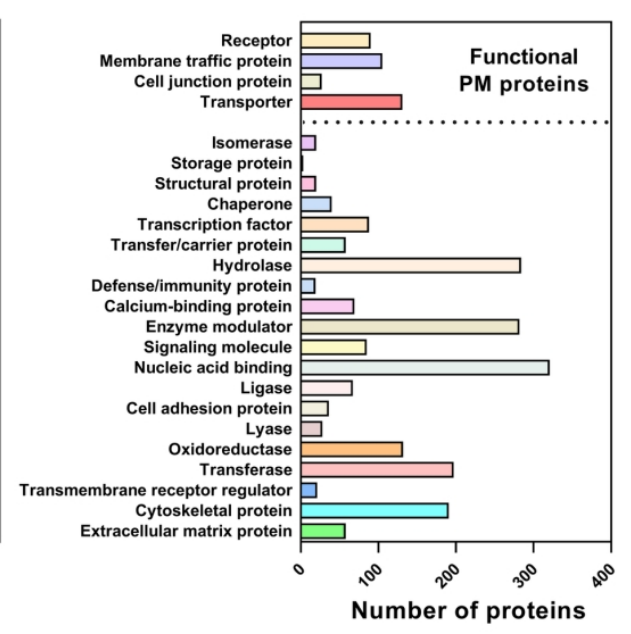

D

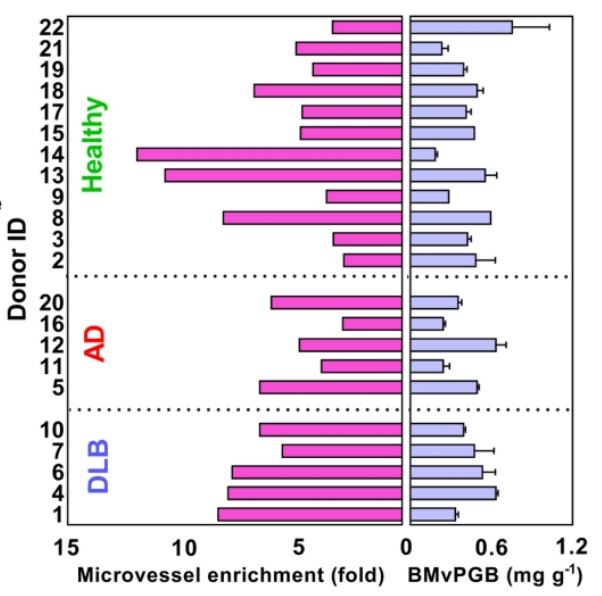

Figure 2: Global proteomic analysis of brain microvascular proteins showing the localization of the proteins (A), their functional class (B), and membrane and transporter protein classes. Other transporters (C, lower pie) refer to non-drug transporters, including, for example, ion transporters (C). Brain microvessel protein per gram brain was assessed in the microvascular fraction and ATPase activity allowed assessment of the level of enrichment of each of the 22 brains microvessel samples relative to their homogenates (D); $A B C$, ATP-binding cassette transporters; AD, Alzheimer's disease; BMvPGB, brain microvessel protein per gram brain; DLB, dementia with Lewy bodies; ER, endoplasmic reticulum; PM, plasma membrane; SLC, solute carriers. In $A$, percentages add to more than $100 \%$ due to expression of proteins in more than one subcellular location.

$152 \times 202 \mathrm{~mm}(300 \times 300 \mathrm{DPI})$ 
Figure 3: Expression of blood-brain barrier (BBB) markers and transporters using MRM targeted proteomics. The abundances of the marker proteins of the neurovascular unit $(A)$ showing markers for endothelial cells (GLUT1, PECAM1), neurons (SYP), astrocytes (GFAP), and pericytes (NG2); ATP1A1 is used as a plasma membrane marker for quality control and also as a reference for global proteomic quantification. After assessment of the purity of the microvascular fraction, the abundance of ABC and SLC transporters was quantified at the blood-brain barrier (B). Three sets of samples were assessed: healthy, AD and DLB, and ratios of average expression in $A D$ and DLB sets relative the healthy set were calculated to assess differences $(C)$. Only ratios $>1.5$ or $<0.67$ (horizontal lines) with statistical significance (stars) were considered meaningful; ABC, ATP-binding cassette transporters; AD, Alzheimer's disease; DLB, dementia with Lewy bodies; SLC, solute carrier transporters; *, $\mathrm{p}<0.05$; **, $\mathrm{p}<0.01$.

\section{$203 \times 186 \mathrm{~mm}(300 \times 300$ DPI $)$}




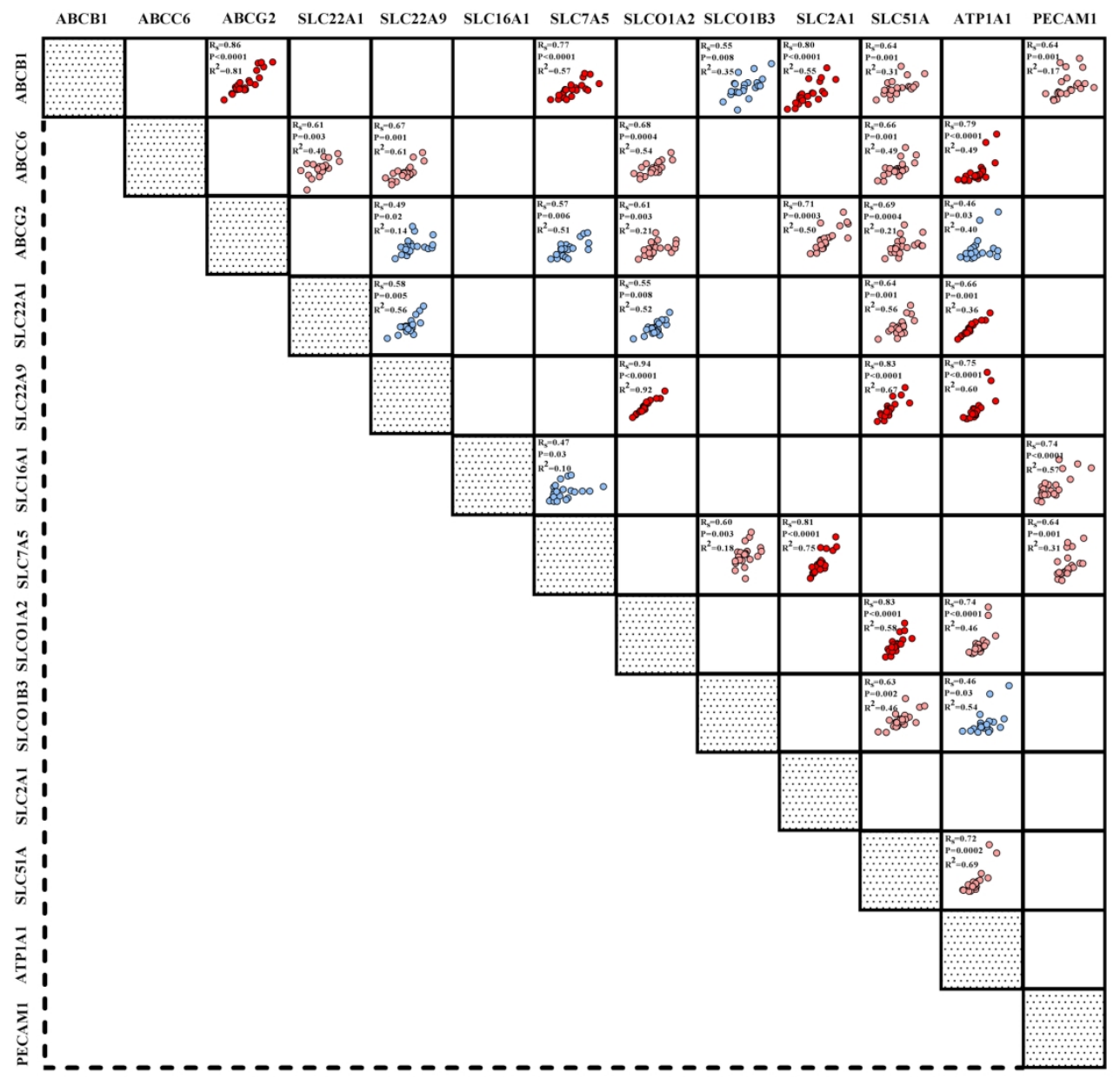

Figure 4: Summary matrix of correlation analysis of ABC, SLC transporters and cell markers expression data. R2, linear regression correlation coefficient; Rs, Spearman Rank order correlation coefficient; only significant correlations are shown; transporters with strong correlation (Rs > 0.75 ) are marked with dark red; moderate correlations (Rs $>0.60$ ) are marked with faint red; correlations with (Rs $<0.60)$ are marked with faint blue. R2 > 0.30 is considered for limited scatter. Number of samples $n=21-22$.

$181 \times 177 \mathrm{~mm}(300 \times 300 \mathrm{DPI})$ 


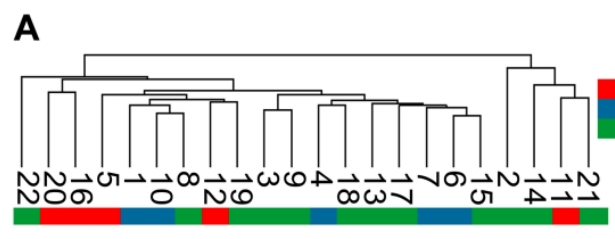

B

Proteins
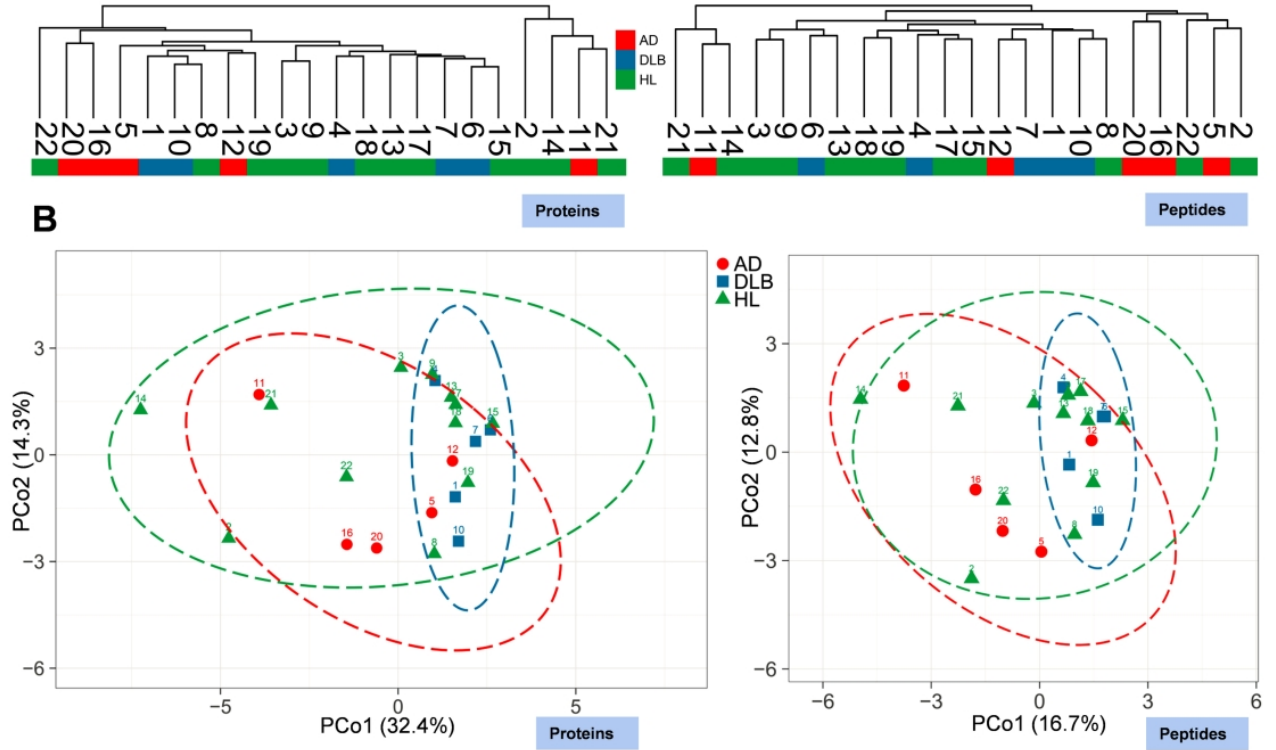

Figure 5: (A) Hierarchical cluster analysis (HCA) and (B) principal coordinates analysis (PCoA) of peptide and protein data for samples from healthy donors $(H$, green symbols) and patients with Alzheimer's disease (AD, red symbols) or dementia with Lewy bodies (DLB, blue symbols). The ellipses represent $95 \%$ confidence intervals. The ages of healthy donors outside the cluster were 54 (donor 2), 87 (donor 14), 89 (donor 21 ) and 90 (donor 22). Analysis of peptide and protein data returned confirmatory results.

$256 \times 159 \mathrm{~mm}(300 \times 300 \mathrm{DPI})$ 


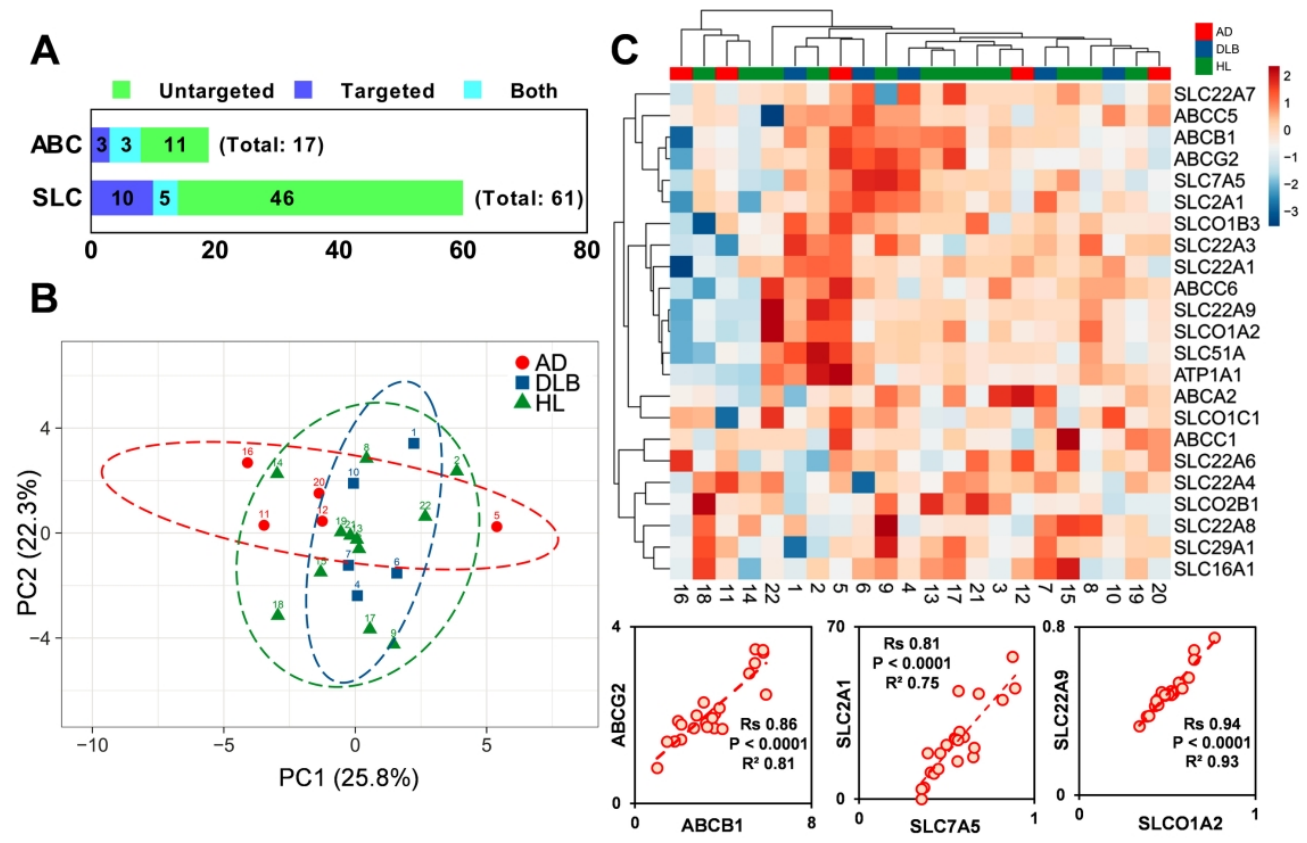

Figure 6: Analysis of the expression of transporters at the blood-brain barrier (BBB): (A) the number of ATPbinding cassette $(A B C)$ and solute carrier (SLC) transporters identified using global and targeted proteomics. The total number of transporters is shown in brackets. (B) Principal components analysis (PCA) of targeted transporter data for samples from healthy donors ( $H$, green symbols) and patients with Alzheimer's disease (AD, red symbols) or dementia with Lewy bodies (DLB, blue symbols). The ellipses represent $95 \%$ confidence intervals. The data were confirmatory of global protein and peptide cluster analysis. (C) HCA and heat map with correlation analysis of transporters protein expression. The associations between the genes (rows) were assessed using correlation analysis, whereas the hierarchical cluster analysis of the samples (columns) was based on Euclidian distance. The heat map is based on log-transformed abundance data.

$224 \times 146 \mathrm{~mm}(300 \times 300 \mathrm{DPI})$ 
B

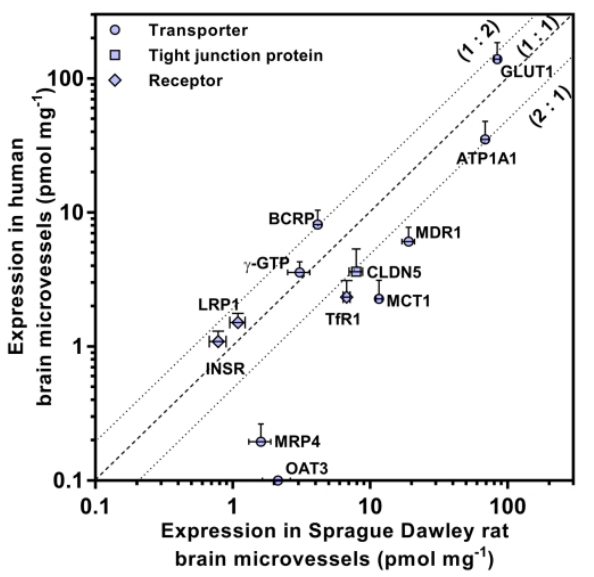

Figure 7: A comparison of protein expression levels of transporters in brain capillaries between Sprague Dawley rat and human using (A) in-house data 20 and (B) literature data.30,17

$149 \times 77 \mathrm{~mm}(600 \times 600 \mathrm{DPI})$ 

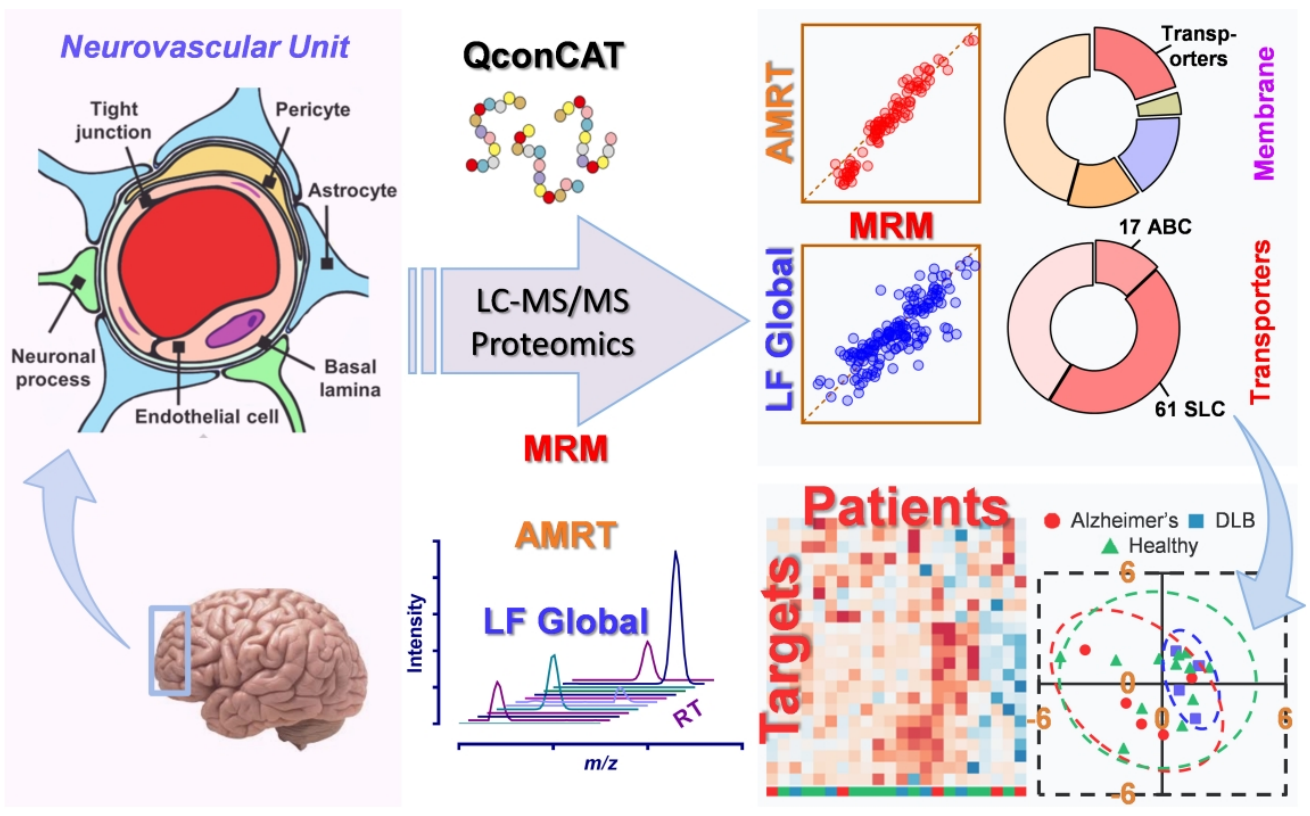

TOC

Graphical abstract

$307 \times 188 \mathrm{~mm}$ (300 x 300 DPI) 